\title{
Research Paper \\ Comparison of the efficacy of acceptance and commitment-based therapy and schema therapy on self-efficacy and craving for change in addicts
}

\section{Fatemeh Bahramabadian ${ }^{1}$, Mina Mojtabaie ${ }^{2}$, Mehrdad Sabet ${ }^{3}$}

1. Ph.D Student Psychology, Department of Clinical Psychology, Roudehen Branch, Islamic Azad University, Tehran, Iran. 2. Associate Professor, Department of Clinical Psychology, Roudehen Branch, Islamic Azad University, Tehran, Iran.

3. Assistant Professor, Department of Psychology, Roudehen Branch, Islamic Azad University, Tehran, Iran.

Citation: Bahramabadian F, Mojtabaie M, Sabet M. Comparison of the efficacy of acceptance and commitment-based therapy and schema therapy on self-efficacy and craving for change in addicts. $\mathrm{J}$ of Psychological Science. 2021; 20(106): 1849-1863.

URL: https://psychologicalscience.ir/article-1-1310-fa.html
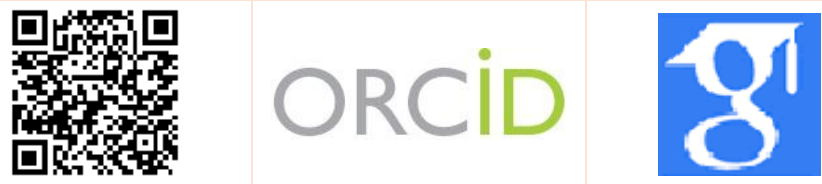

\section{A R T I C L E I N F O A B S T R A C T}

Keywords:

Acceptance

Commitment Therapy

Schema Therapy,

Self-Efficacy,

Craving for Change,

Addicted to drugs

Received: 26 Jun 2021

Accepted: 24 Jul 2021

Available: 22 Dec 2021
Background: Studies have shown that low self-efficacy and poor beliefs in abilities in stressful situations are two causes of substance abuse and relapse of addictive behaviors.

Aims: This study aims to compare the effectiveness of acceptance and commitment therapy and schema therapy on self-efficacy and Craving for Change in Addicts.

Methods: The present study was a quasi-experimental study with a pretest-posttest design with a control group and a 2-month follow-up period. The target group of this study includs all male addicts who are involved in the material 16 of Gilan province, 45 people It was estimated and selected by convenience sampling method and randomly assigned to experimental and control groups. Group intervention based on acceptance and commitment therapy (Peterson, Eifert, Feingold \& Davidson, 2012) and schema therapy (Young, Klosko \& Weishaar, 2003) were performed in 81 -hour sessions in the experimental group. The research instruments included Scherer and Maddox (1982) selfefficacy questionnaires and Miller and Tunigan (1996) Readiness for Change and Enthusiasm Questionnaire. Data analysis was performed using mixed analysis of variance.

Results: The results showed that acceptance and commitment therapy and schema therapy had a highly significant effect on increasing self-efficacy with two-month follow-up $(\mathrm{P}<0.001)$. Also, acceptance and commitment therapy and schema therapy on the Craving to change with Two-month follow-up ( $\mathrm{P}<0.001)$ had a highly significant effect, but there was no significant difference between the effectiveness of acceptance and commitment-based therapy and schema therapy on self-efficacy and craving for change in patients undergoing treatment.

Conclusion: Acceptance and commitment therapy, and schema therapy increased self-efficacy and the craving for change in addicts, and were able to move forward the addicted individuals from the stage of determination and readiness to the stage of action and retention.

* Corresponding Author: Mina Mojtabaie, Associate Professor, Department of Clinical Psychology, Roudehen Branch, Islamic Azad University, Tehran, Iran.

E-mail: mojtabaie_mina@yahoo.com

Tel: (+98) 9124093679

2476-5740/ (C) 2021 The Authors. This is an open access article under the CC BY-NC-ND license

(https://creativecommons.org/licenses/by-nc/4.0/). 


\section{Monthly Journal of Psychological Science}

\section{Extended Abstract}

\section{Introduction}

Today, the problem of drug abuse has become so acute that it is considered as one of the four major crises of the present age, along with the nuclear threat, environmental pollution and poverty. According to semi-official statistics, this anomaly, in the most optimistic case, has made $12.1 \%$ of the total population of Iran dependent or abusive of drugs. Since the human race began abusing drugs, many efforts have been made to prevent and treat addiction. Has been done (Hajipoor, Bayazi \& Nejat, 2020). Some addicts seek treatment, which they call selfintroduced addicts, and others avoid treatment, which are called addicts. Article 1 of the Anti-Narcotics Law provides for compulsory treatment for drug addicts. People who do not volunteer for treatment and in that case are subject to Article 16 of the law, i.e., the judge must oblige him to act for his treatment and he is recognized as a perpetrator and is referred to Article 16 centers or compulsory treatment (Pournaghash Tehrani, Malekahmad \& Lavasani, 2021).

On the other hand, Marlat (1996) mentions low selfefficacy in examining the etiology of substance abuse and relapse of forced behaviors. Self-efficacy is one of the important concepts in Bandarva cognitivesocial theory and means confidence, belief and belief in one's abilities to control one's thoughts, feelings, activities and effective performance in stressful situations. In this regard, Nikmanesh, Baluchi, Pirasteh Motlagh (2017) in their research have concluded that self-efficacy is an important factor in the return of people to drug use and this issue is significant in the process of treatment of addicts and the temptation to reuse drugs.

Readiness and willingness to quit addiction is another very important aspect of addiction. Among these, the motivation to quit is substance as an important part of the phenomenon of addiction, which consists of two components: the intensity of a person's desire to quit and the component of why and nature of motivation (Curry, Grothaus \& McBride, 1997). According to the exchange model the motivation for changing addictive behaviors consists of five stages: prethinking, thinking, preparing, acting, and
Vol. 20, No. 106, Winter(January) 2021

maintaining, each with its own unique cognitive and behavioral elements. The theoretical exchange model includes a cognitive-behavioral cycle that begins with not having a plan to quit (pre-thinking) and continues until the maintenance of addiction-quitting behaviors (maintenance) (Abiola, Udofia, Sheikh \& Sanni, 2015). One of the leading interventions in addiction treatment and relapse prevention in recent years is psychological modeling, including schema therapy training and acceptance and commitment-based therapy that helps the patient to acquire the necessary skills to manage risky situations and treatment. Focuses on associated psychological disorders (Miller, Wilbourne \& Hettema, 2003).

Considering the theoretical foundations of the research and the role of schema therapy and psychotherapy based on acceptance and commitment as key factors in relation to prevention and treatment of substance abuse and research gaps in this field, using the results of this research to increase selfefficacy and craving for change. It is one of the important necessities of this study and in the present study, the researcher aims to compare the effectiveness of treatment based on acceptance and commitment and schema therapy on increasing selfefficacy and craving for change in addicts.

\section{Method}

Based on the designed objectives, this study was an applied research and in terms of method, quasiexperimental and using a pre-test post-test design and a control group with a follow-up period. The study population included all male addicts in the Article 16 target group in Gilan province, Rasht city, whose number was 1000 people. Of these, 45 used the Cohen table with an effect size of 89/. And test power 84/. It has been estimated were selected using available sampling method and were randomly assigned to experimental and control groups.

In order to collect data, self-efficacy questionnaires and stages of readiness for change and enthusiasm for addiction treatment were used. Self-efficacy and willingness to change questionnaires were administered to all three groups, then the two experimental groups underwent 8 one-hour sessions of treatment based on acceptance and commitment and group schema therapy, but the control group did 


\section{Monthly Journal of Psychological Science}

Vol. 20, No. 106, Winter(January) 2021

not receive any treatment and after the interventions, the participants in all three groups answered the questionnaires of self-efficacy and desire for change (post-test). Finally, after two months, participants in the study were asked about self-efficacy and desire to change.

Self-efficacy questionnaires and stages of readiness for change and eagerness to treat addiction were provided to the sample group and they were assured that their information would be kept confidential and collected only for research work and it was emphasized that they answer the questions honestly. Finally, after collecting the questionnaires, the data were analyzed by SPSS software version 22. Mixed analysis of variance was used to test the research hypothesis.

\section{Results}

In this study, 45 addicts (30 in the acceptance and commitment-based treatment experimental groups and 15 in the control group) were studied. Also, the mean and standard deviation of the age of patients in the study age group was 18 to 30 years, with the highest percentage, $66.9 \%$, being in the age group of 23 to 26 years, of which 21 were single and 9 were married. In Table 1, the mean and standard deviation of research variables in pre-test, post-test and followup and separately for experimental and control groups are reported.

Table 1. Mean and standard deviation of subjects' scores in research variables

\begin{tabular}{cccccccc}
\hline \multirow{2}{*}{ Variable } & \multirow{2}{*}{ Groups } & \multicolumn{2}{c}{ ACT } & \multicolumn{2}{c}{ ST } & \multicolumn{2}{c}{ Control } \\
\cline { 3 - 8 } & & $\mathrm{M}$ & $\mathrm{SD}$ & $\mathrm{M}$ & $\mathrm{SD}$ & $\mathrm{M}$ & SD \\
\hline \multirow{2}{*}{ Self-Efficacy } & Pre-test & 52.20 & 5.04 & 51.80 & 4.34 & 52.33 & 4.13 \\
& Post-test & 58.60 & 3.60 & 58.93 & 4.01 & 55.40 & 3.39 \\
\multirow{2}{*}{ Craving for change } & Pre-test & 21.86 & 2.50 & 26.04 & 2.47 & 26.20 & 2.33 \\
& Post-test & 32.06 & 2.65 & 35.53 & 2.41 & 26.73 & 3.17 \\
\hline
\end{tabular}

\section{Conclusion}

The aim of the present study was to compare the effectiveness of acceptance and commitment-based therapy and schema therapy on self-efficacy and craving for change in addicts. The results of the present study showed that treatment based on acceptance and commitment and schema therapy have been effective on self-efficacy and desire for change in addicts. But there is no difference between the effectiveness of acceptance and commitment therapy and schema therapy on self-efficacy and the desire for change in addicts.

Given that in schema therapy, patients' deep problems are defined more precisely and the traces of schemas are followed by emphasizing the interpersonal relationships of the individual and patients realize the roots of their dysfunctional coping behaviors, there is a lot of motivation. They find to get rid of their problems. Schemas of entitlement, inadequate restraint, self-sacrifice, acceptance and obedience have been identified as the main schemas of re-use and during treatment sessions as well as the desire to get rid of his problems, the person puts a lot of effort and as a result less temptation and will report a desire for further change. Schema therapy also helps addicts to adopt healthier strategies other than substance use to counteract internal stimuli and encourages change in individuals (Karekla \& Savvides, 2021).

Schema therapy seems to help a person become aware of and accept emotions, and therapy based on acceptance and commitment results in a judgmental and balanced sense of awareness. Therefore, it can be said that performing therapy exercises based on acceptance and commitment and schema therapy causes the person to be aware of his emotions and accept emotions, and as a result, increases selfefficacy and desire for change in people. Therefore, it can be said that both therapeutic approaches in their own way have sustained their effects on self-efficacy and desire for change, and there is no difference between them in terms of sustainability (Hayes, Levin, Plumb-Vilardaga, Villatte \& Pistorello, 2013). One of the limitations of this study is the limited number of addicted people in Gilan province, Rasht city, which makes the generalization of the findings with caution. Also, the present study has several theoretical and practical implications. Due to the fact that in the present study, gender differences have not 
been studied, it is suggested that in future research, the effectiveness of acceptance and commitment therapy and schema therapy (male and female) be compared. It can also be considered to inform patients, psychologists and counselors and patients' families about the effectiveness of these interventions and to develop programs to familiarize patients, psychologists and counselors and families with these interventions.

\section{Ethical Considerations}

Compliance with ethical guidelines: This research is taken from the dissertation of the first author in the Islamic Azad University of Roodehen. It should be noted that in this research, the researcher, after obtaining approval from the ethics committee, IR.GUMS.REC.1400.083 conducted the research process.

Funding: This study was conducted without the financial support of any public or private institution or organization.

Authors' contribution: The first author is responsible for obtaining licenses, implementing protocols and questionnaires; The second author was responsible for writing the Persian and English abstracts, the introduction and the background of the research, and the third author was responsible for writing the conclusions, sources and formatting.

Conflict of interest: This research has not had any conflict of interest for the authors.

Acknowledgments: The authors would like to thank all the people who participated in this study. 


\title{
مقايسه اثربخشى درمان مبتنى بر يذيرش و تعهل و طرحواره درمانى بر خود كار آملى و اشتياق به تغيير در افراد معتاد متجحاهر
}

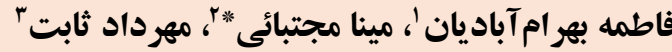

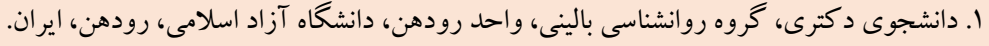

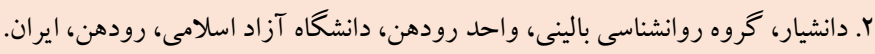

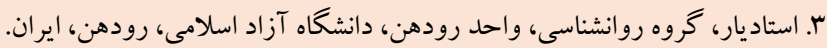

\begin{tabular}{|c|c|}
\hline جكيده & 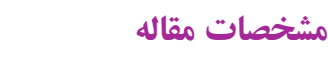 \\
\hline زمينه: بررسىهاى صورت گرفته نشان داده است خود كار آمدى بايين و باور ضعيف نسبت به توانايى در شرايط تنش آور از علل سوء مصرف & كليدوازهها: \\
\hline مواد و باز گشت رفتارهاى اعتيادى است. & درمان مبتى بر يذيرش و تعهد، \\
\hline هدف: يُوهش حاضر با هدف مقايسه اثربخشى درمان مبتنى بر يذيرش و تعهد و طرحواره درمانى بر خود كار آمدى و اشتياق به تغيير در & 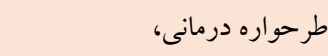 \\
\hline 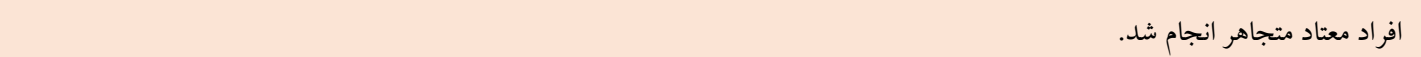 & 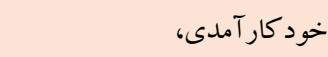 \\
\hline 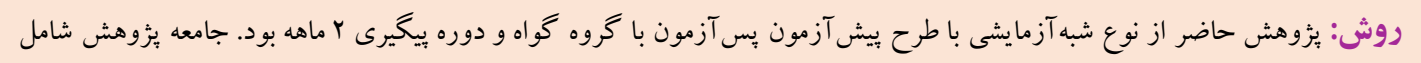 & 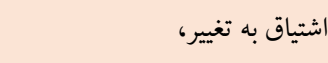 \\
\hline كليه معتادان مرد متجاهر گروه هدف ماده 19 استان گيلان بودند هץ نفر كه با روش نمونه گيرى در دسترس انتخاب و با كمارش تصادفى & معتاد متجاهر \\
\hline 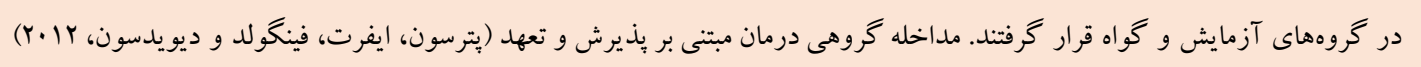 & \\
\hline 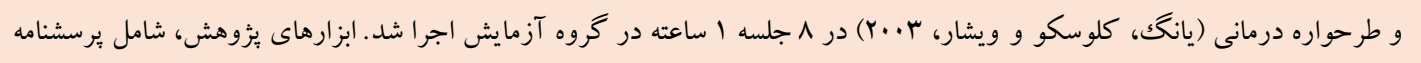 & \\
\hline هاى خود كار آمدى شرر و مادو كس (raA1) و مراحل آمادگى براى تغيير و اشتياق براى درمان اعتياد ميلر و تونيكان (1999) بود. تحليل & \\
\hline دادها با روش تحليل واريانس مختلط انجام شد. & \\
\hline 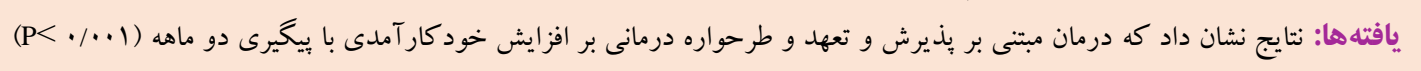 & \\
\hline 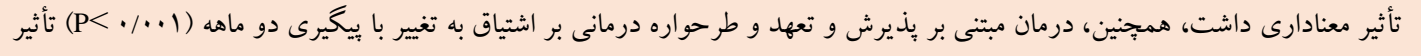 & \\
\hline معنادارى داشت، اما بين اثربخشى درمان مبتنى بر بذيرش و تعهد و طرحواره درمانى بر خود كار آمدى و اشتياق به تغيير در افراد متجاهر در & \\
\hline درمان ماده 19 تفاوت معنادارى وجو د نداشت. & 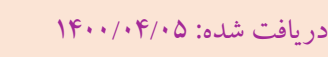 \\
\hline نتيجه كيرى: درمانهاى مبتنى بر يذيرش و تعهد و طرحواره درمانى منجر به افزايش خود كار آمدى و اشتياق به تغيير در فرد معتاد گرديد و & 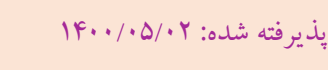 \\
\hline توانست فرد وابسته به مصرف مواد مخدر را از مرحله عزم و آماد گى به مر حله اقدام و ابقاء برساند. & 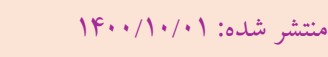 \\
\hline
\end{tabular}

* نويسنده مسئول: مينا مجتبائى، دانشيار، گروه روانشناسى بالينى، واحد رودهن، دانشكاه آزاد اسلامى، رودهن، ايران. رايانامه: mojtabaie_mina@yahoo.com 
تو انايىهاى خويش در كنترل افكار، احساسها، فعاليتها و عملكرد مؤثر او در شرايط استرسزاست. در همين راستا نيككمنش، بلوجى، ييرسته مطلق (Y.IV)

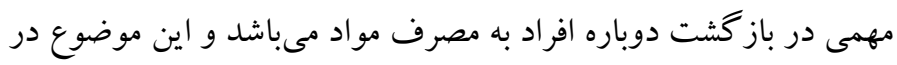
فرايند درمان معتادين و وسوسه استفاده مجدد مواد قابل توجه است.

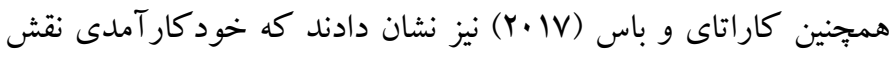
مهمى در جلو گيرى از گرايش به اعتياد دارد. آمادگى و تمايل به ترك ده

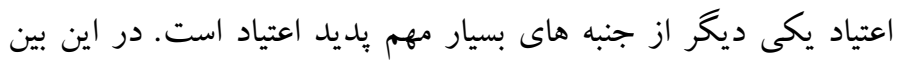

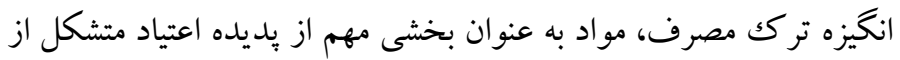

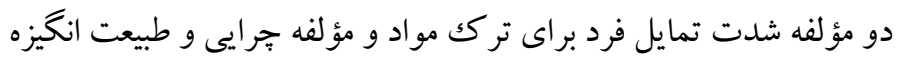

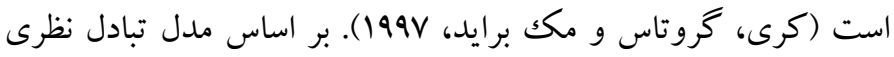

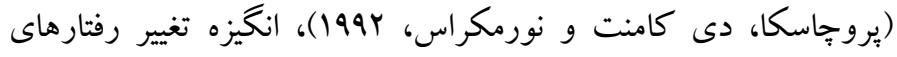

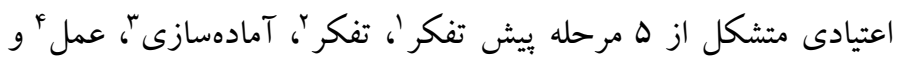

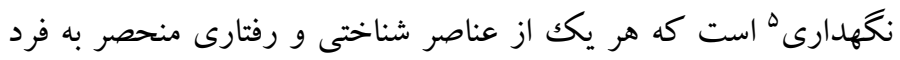

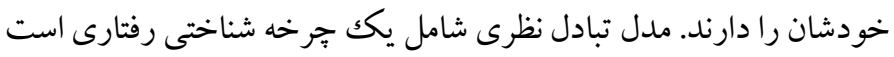

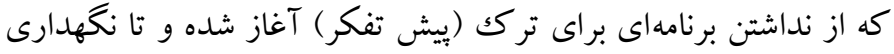

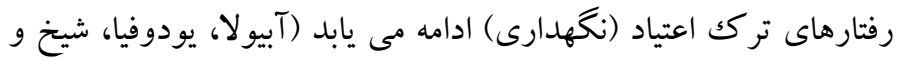

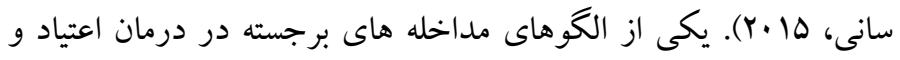

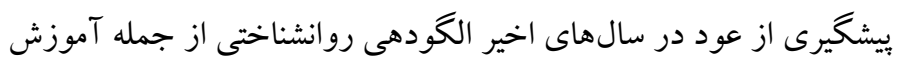

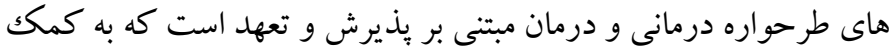

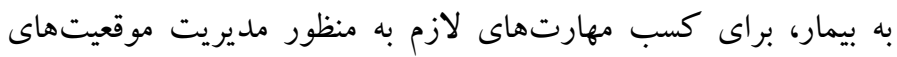

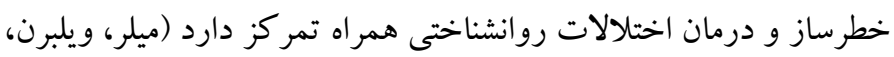

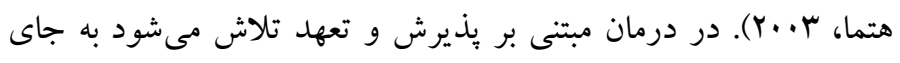
تغيير شناختها، ارتباط روانشناختى فرد با افكار و احساساتش افزايش يابد.

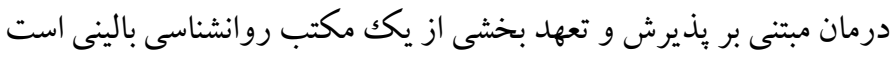

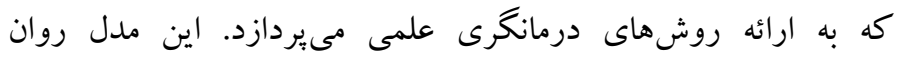
درمانگرى جديد بخشى از آن جه امروز به موج سوم درمان ناميده مى دود

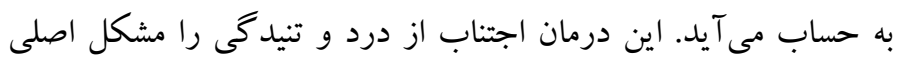

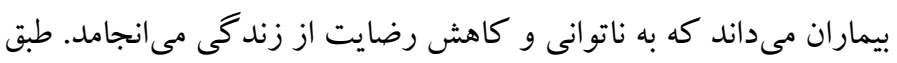
اين نظريه، اجتناب زمانى اتفاق مىافتد كه افكار و هيجانات منفى اثر مفرط ونى

${ }^{4}$. action

${ }^{5}$. maintenance
مقام امروزه، مشكل سوء مصرف مواد مخدر، جنان شدت يافته كه به عنوان

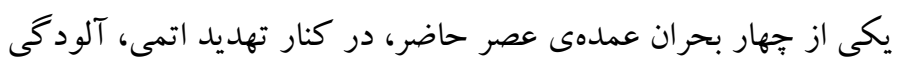

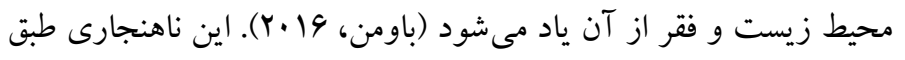
آمار نيمه رسمى، در خوشبينانه ترين حالت / I ا درصد از كل جمعيت ايران را وابسته يا سوء مصرف كننده مواد ساخته است از زمانى كه نوع انسان سوء مصرف مواد را آغاز كرده است، تلاشهاى فراوانى نيز براى بيشخيرى و درمان اعتياد صورت گرفته است (حاجىيور و همكاران،

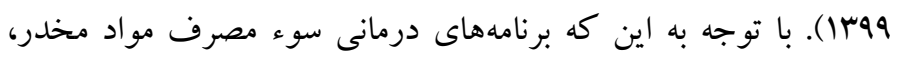
هزينه مالى سنخينى را بر دوش جوامع مى گذارد، سبب شناسى و ويشخيرى از عو امل مؤثر بر سوء مصرف مواد مخدر ضرورى است (بييير و همكاران،

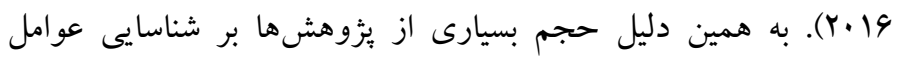

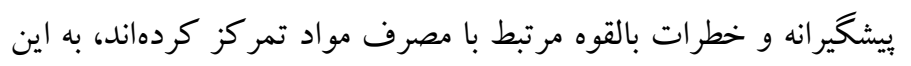
اميد كه شناسايى گروههاى در معرض خطر به راهبردهاى مؤثرى براى براى

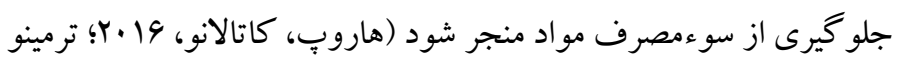
همكاران، Y.19). بعضى از معتادين خواستار درمان هستند كه به آنها معتادين خودمعرف مى گويند و بعضى ديخر از درمان فرار مى كنند كه

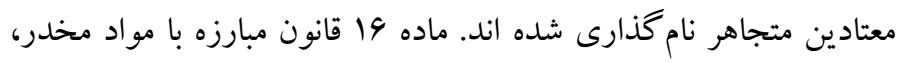
درمان اجبارى را براى معتادين متجاهر صادر كرده است. افرادى كه براى

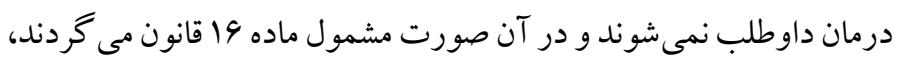
يعنى قاضى او را بايد ملزم كند كه براى درمان خود اقدام كند و متجاهر

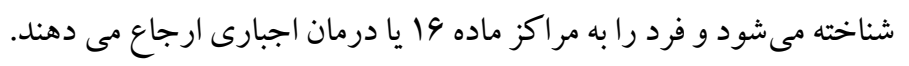

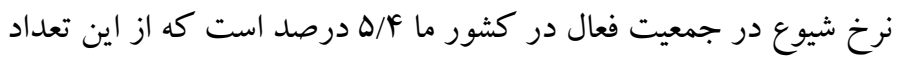

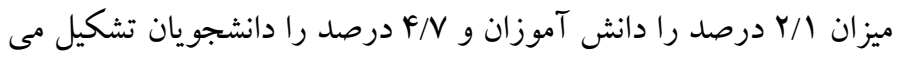
دهند كه درگير اعتياد شدهاند (يورنقاشتهرانى، ملككاحمد و غلامعلى دروان

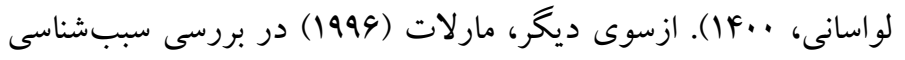

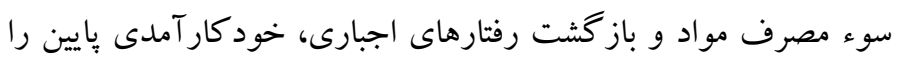

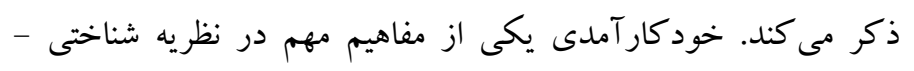

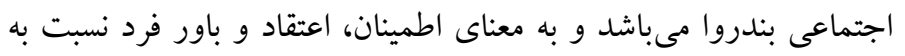

1 . pre-contemplation 2 . contemplation 3 . preparation 
كه درمان يذيرش و تعهل در كاهش ميل و ولع مصرف در بيماران معتاد به

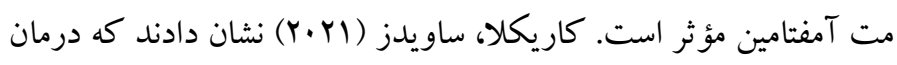
بذيرش و تعهل در تركك سيخار در دانشجويان مؤثر بوده است. هرتز و ايوانز (Y.YI)

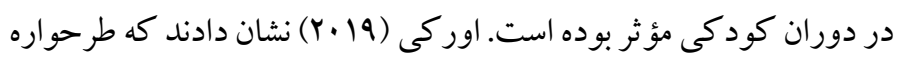

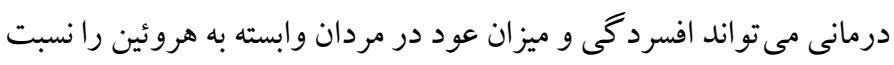

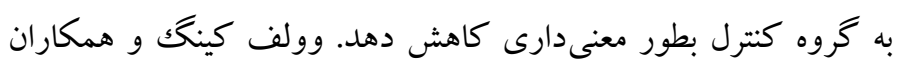
ACT براى بيماران سوء مصرف الكل مؤثر

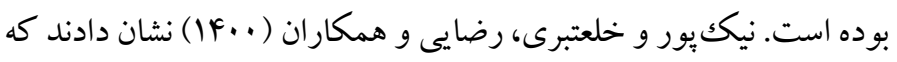

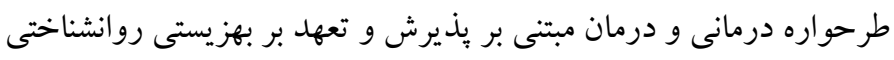

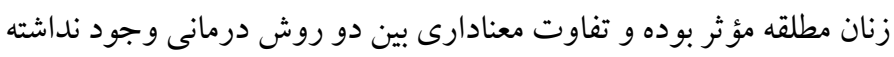

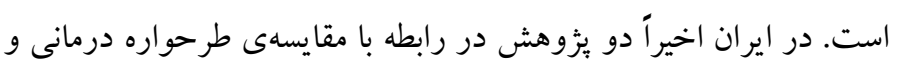

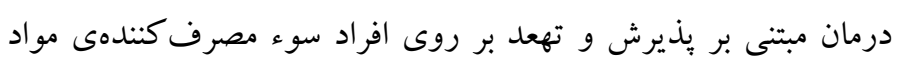
انجام شد؛ اما نتايج بدست آمده تفاوتى را در ميان اين دو درمان نشان نشان ندان

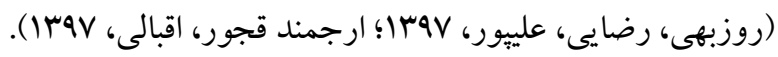
درمان مبتنى بر يذيرش و تعهل و طرحواره درمانى نسل جديدى از از درمان هاى شناختى رفتارى محسوب مى شود كه انعطاف يذيرى روانشناختى را

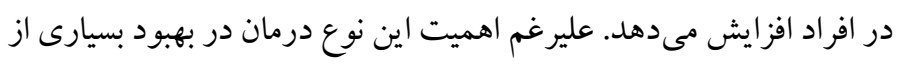
مراجعين به خصوص در حيطه مشكلات فردى خانوادگى و آسيبهاى

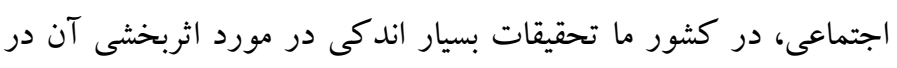

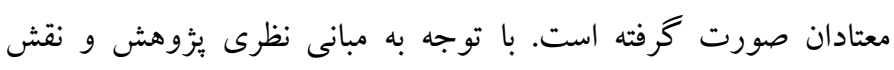

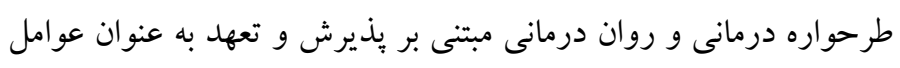

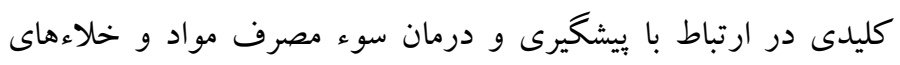

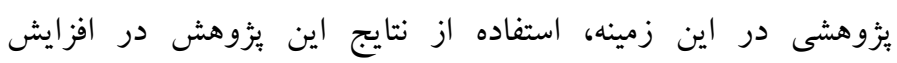
خود كار آمدى و اشتياق به تغيير از ضرورت هاى مهم اين مطالعه است. در درد

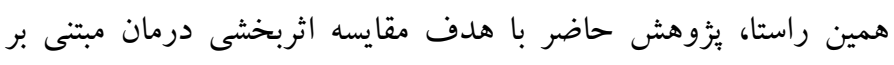

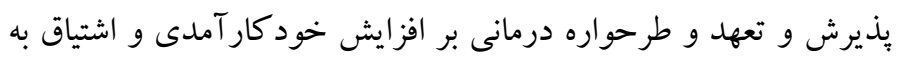
تغيير در افراد معتاد متجاهر انجام شد.

روش الف) طرح هؤوهش و شر كت كنند أن: بر اساس اهداف طراحى شده، اين يزوهش از نوع تحقيقات كاربردى و به لحاظ روش، شبه آزمايشى و
و نامناسب بر رفتار مى گذارند. بنابراين شيوه اصلى درمان مبتنى بر بذيرش

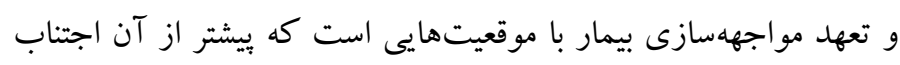

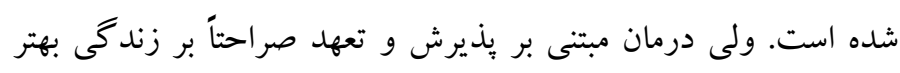

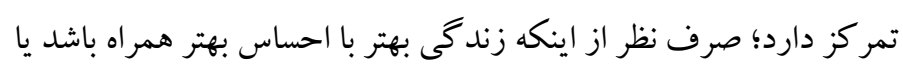

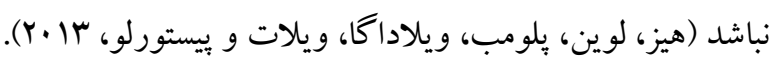

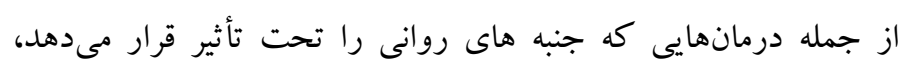

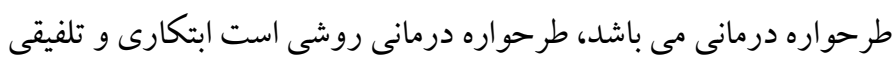

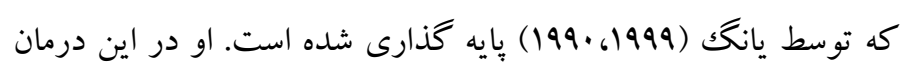
كوشيده است تا با به كار گيرى مبانى و راهبردهاى درمان شناختى - رفتارى (CBT)

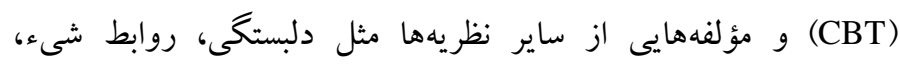

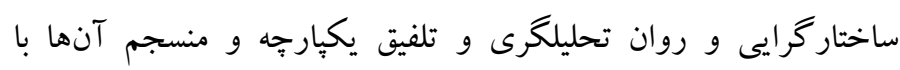

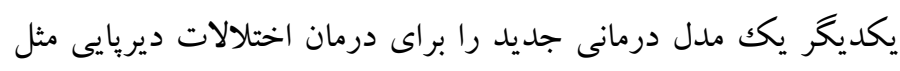

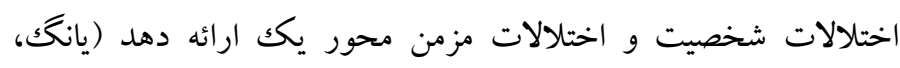

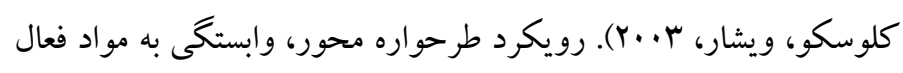

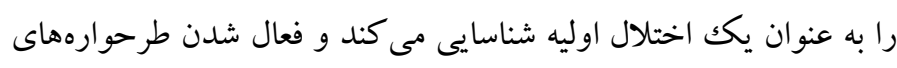

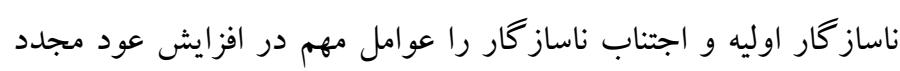

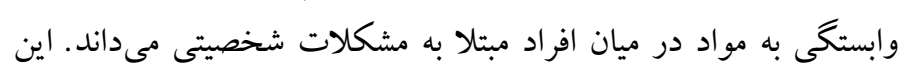

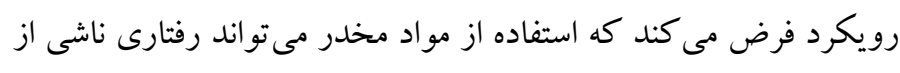
ابراز مستقيم فعاليت طرحوارههاى استحقاق و خويشتندارى ناكافى يا

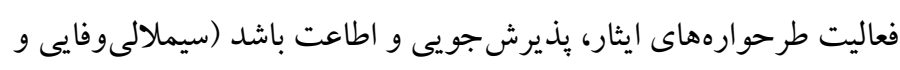

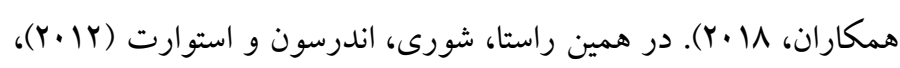

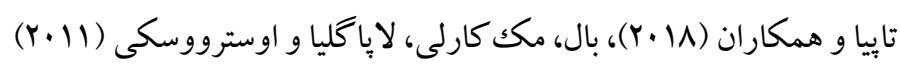
در بثزوهش هاى خود به اين نتيجه رسيدند كه درمانهاى مؤثرى از جمله طرحواره درمانى و شناخت درمانى به كاهش طرحو ارههاى ناساز گار اوليه در ميان افراد مبتلا به سوءمصرف مو اد كمكك مى كند. در بيزوهشى ديخر،

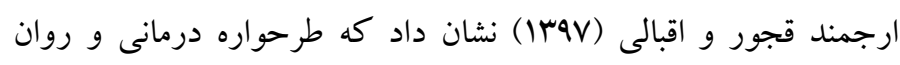

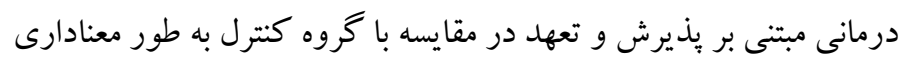

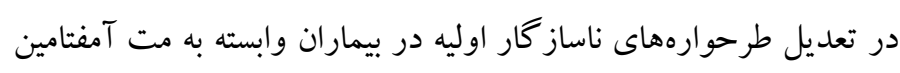

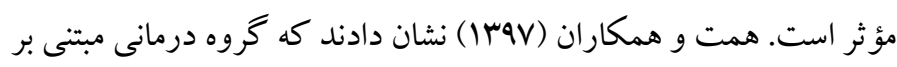

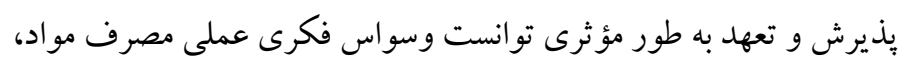

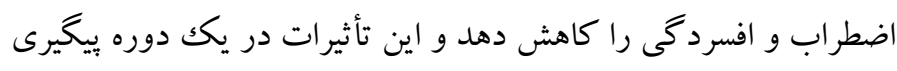

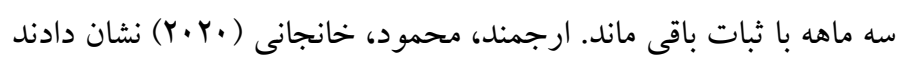


برسشنامه مراحل آمادكى براى تغيير و اشتياق براى درمان اعتياد': اين

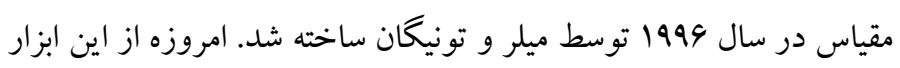

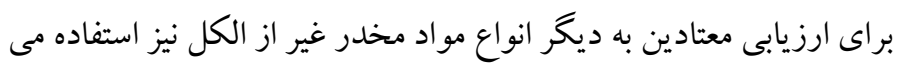

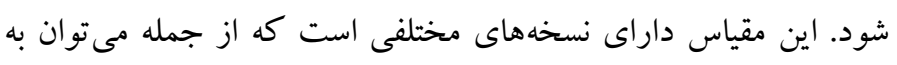
يرسشنامه فردى مصرف مواد / الكل (يرسشنامه حاضر)، كه دارئ مارى 19

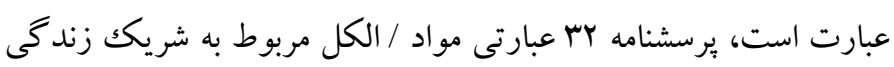

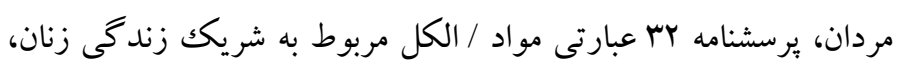
برسشنامه Yr عبارتى الكل مربوط به شريك زند

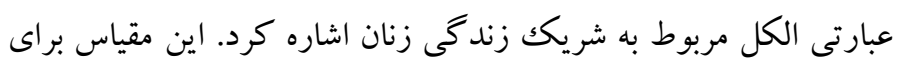

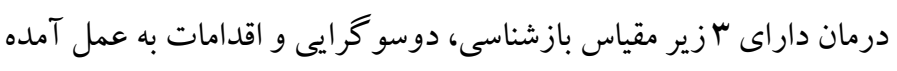

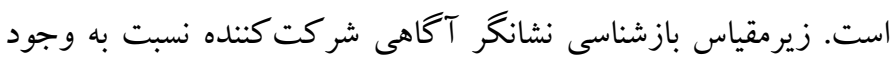

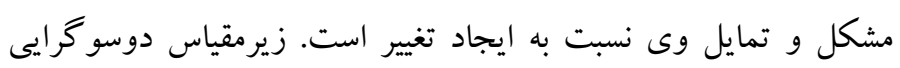

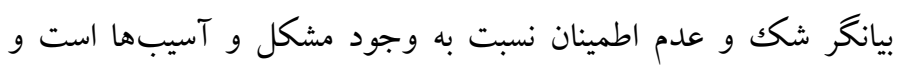

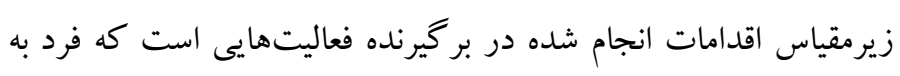

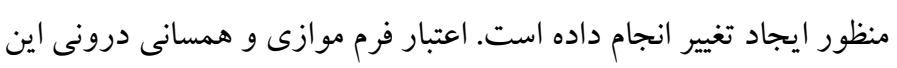

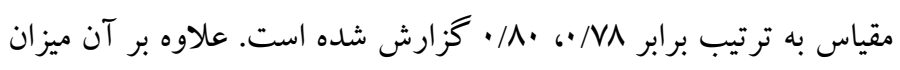

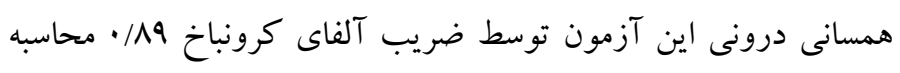
شد كه از نظر معيارهاى روان سنجى مورد تأييد مىباشد (ميلر و تونيكان،

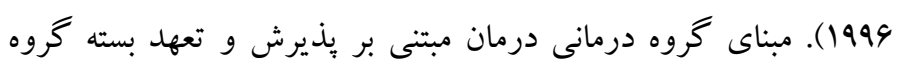

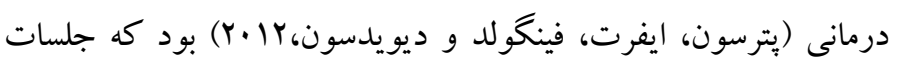

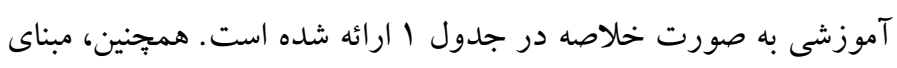
گروه درمانى طرحواره درمانى بسته گروه درمانى (يانگك، كلوسكو و و

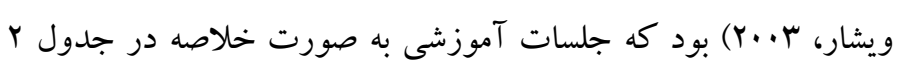
ارائه شده است. برسشنامهاى خود كار آمدى و مراحل آمادكى براى تغيير و اشتياق براى

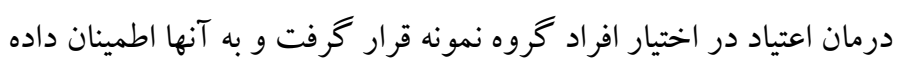

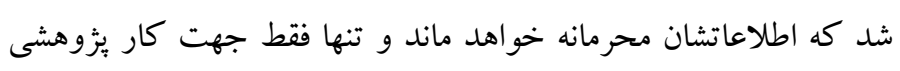
جمع آورى مىشود و تأكيد شد كه صادقانه به سؤالات باسخ دهند. لازم به ذكر است در اين بثزوهش، يزوهشكر بعد از كسب تأييديه از كميته

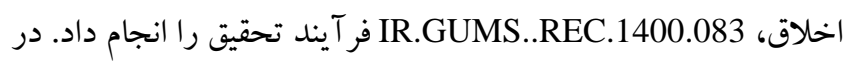

با بهره گيرى از طرح بيش آزمون بس آزمون و گروه گو اه با دوره بيخيرى

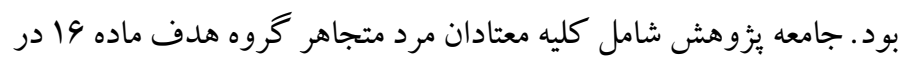

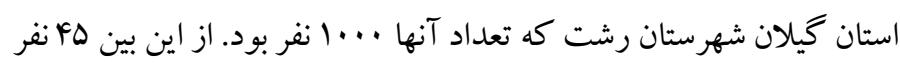

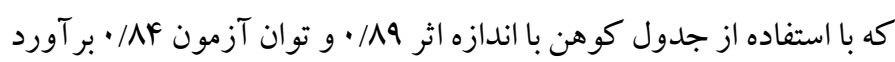

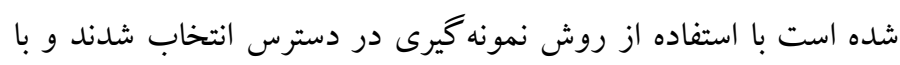

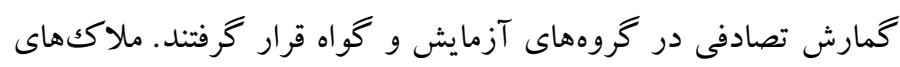

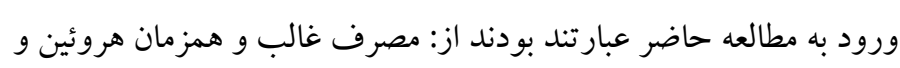
شيشه، مدت اقامت سه ماه، تحت هيج درمان مداخله روانشناختى قرار

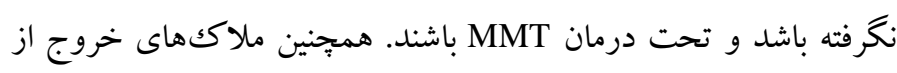
يُزوهش داشتن اختلالات سايكو تيك، كمتر از ب ماه اقامت در مركز داشته ماته باشد. براى هر سه گروه برسشنامه هاى خود كار آمدى و اشتياق به تغيير

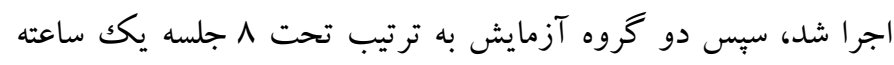

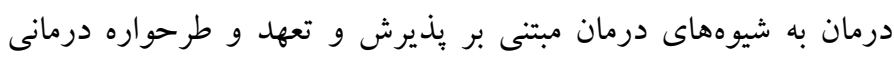

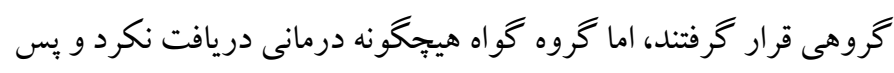

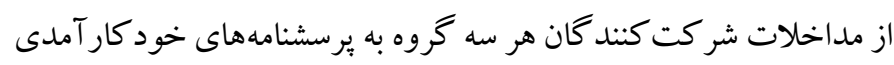

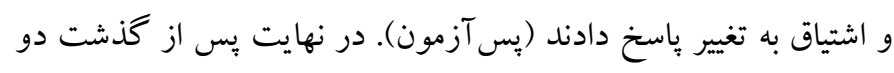

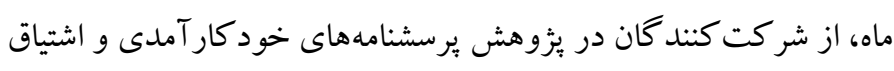
به تغيير كرفته شد.

ب) ابزار برسشنامه خود كار آمدى: اين مقياس در سال به19 آتوسط شرر و مادو كس

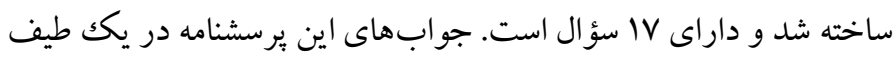

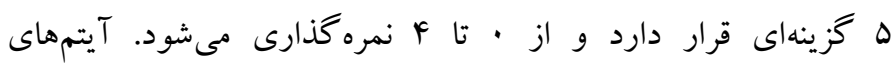


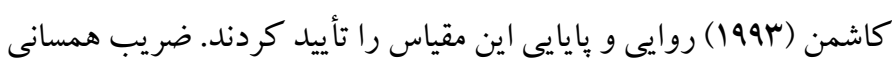

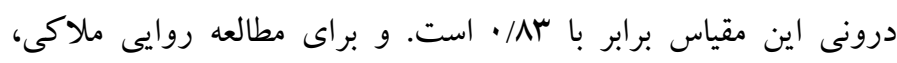

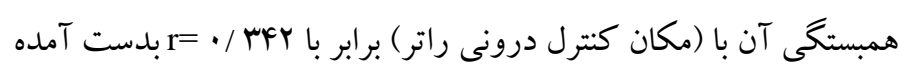

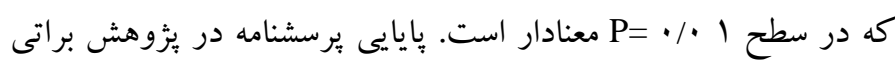

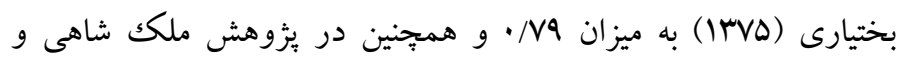

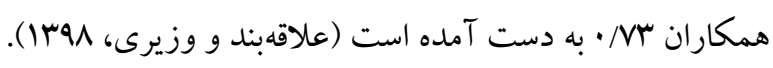

${ }^{1}$. Scale stage of readiness for change and the desire to treat addiction 
نهايت، يس از جمع آورى يرسشنامهها، اطلاعات توسط نرمافزار SPSS $\quad$ Sختلط استفاده شد. نسخه 22 تحليل شدند. براى آزمون فرضيه يُزوهش از تحليل واريانس

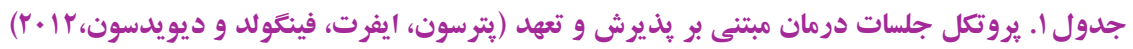

\begin{tabular}{|c|c|c|}
\hline محتوا و تكاليف & اهداف & جلسه \\
\hline يس از آشنايى و ايجاد رابطه حسنه، معرفى درمان مبتنى بر يذيرش و تعهل و معرفى تمرينات و اجراى ييش - & & \\
\hline آزمون. مصاحبه فردى، معرفى مفهوم تغيير رفتار، بيان تفاوت افكار، احساسات و عمل تمرين ذهن آكاهى و & آشنايى و معارفه & اول \\
\hline 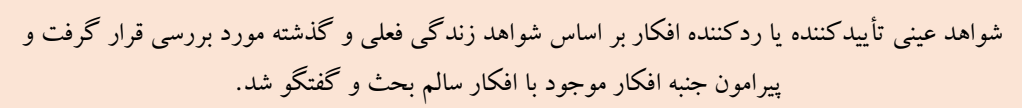 & ارزيابى هزينهاى تلاش هاى رابطه اى بى - اثر & دوم \\
\hline 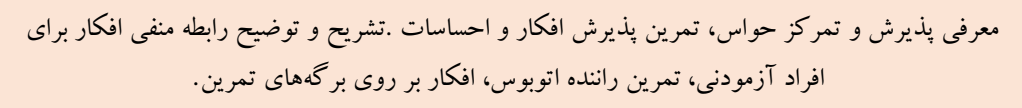 & تمر كز حواس و بذيرش و همجوشى & سوم \\
\hline توسعه ديد گاه ناظر و مقايسه واكنشهاى خود به تنهايى و خود در ارتباط با فرد، افكار بر روى بركههاى & & \\
\hline 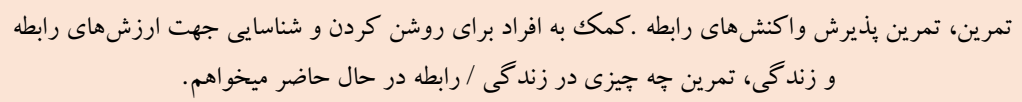 & مشاهده افكار و انتخاب جهت ارزشها & 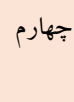 \\
\hline 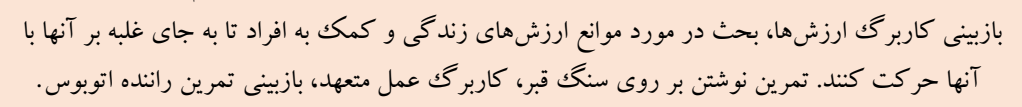 & 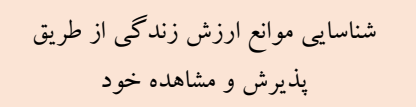 & ينجم \\
\hline معرفى تمايل، بازبينى تمرين راننده اتوبوس و كاربرگك عمل متعهد. & ايجاد الكوهاى انعطافيذير رفتار در رابطه & ششم \\
\hline طبيعت انتخاب و توانايع ياسخ، تجربه داشتن زوجها در خود به عنوان زمينه رابطه، كاربرگك اقدام متعهد، & خود به عنوان زمينه در اين رابطه و & \\
\hline استعاره صفحه شطرنج. بازبينى تمايل عاطفى در يك زمينه عمل متعهد، كاربركى اقدام متعهد. & 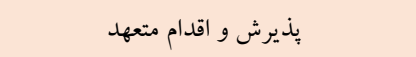 & هعتم \\
\hline بازبينى ارزشهاى رابطه و اقدام متعهد، آمادگى براى اقدام متعهد در آينده و پِايان درمان، و اجراى بِ آزمون & كار در جهت بايان & هشتم \\
\hline
\end{tabular}

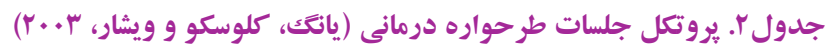

\begin{tabular}{|c|c|c|}
\hline محتواو تكاليف & اهداف & جلسه \\
\hline اهميت و هدف طرحواره درمانى بيان و مشكلات مراجعان در قالب رويكرد طرحواره درمانى صورتبندى مى شود. سنجش مران & ارزيابى و جهت گيرى درمان & اول \\
\hline شو اهد عينى تأييدكننده يا رد كننده طرحوارهها بر اساس شواهد زندگى فعلى و گذشته مورد بررسى قرار گرفت و ييرامون & آشنايى با مفاهيم طرحواره درمان(1) & دوم \\
\hline 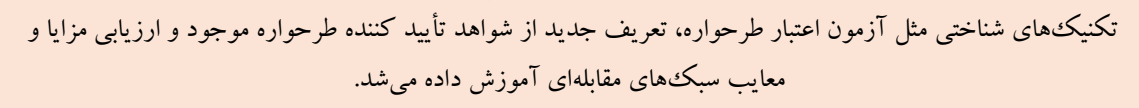 & آشنايى با مفاهيم طرحواره درمانى(Y) & سوم \\
\hline مفهوم بزر گسال سالم در ذهن بيمار تقويت شد، نيازهاى هيجانى ارضا نشده آنها شناسايى و راهكارهاى بيرون ريختن & سنجش و آموزش طرحوارهها & جهارم \\
\hline برقرارى ارتباط سالم و كفتخوى خيالى آموزش داده شد. & شروع فرآيند تغيير طرحوارهها & ينجم \\
\hline تكنيك هاى تجربى مثل تصوير سازى ذهنى موقعيتهاى مشكل آفرين و رويارويى با مشكل ساز ترين آنها آموزش داده شد. & فر آيند تغيير طرحوارهها (1) & ششم \\
\hline رابطه با افراد مهم زندگى و نقش بازى كردن آموزش داده شد. & فرآيند تغيير طرحوارهها(Y) & هفتم \\
\hline مزايا و معايب رفتارهاى سالم و ناسالم مورد بررسى قرار كرفت و راهكارهايى براى غلبه بر موانع تغيير رفتار آموزش داده آزمونهات & 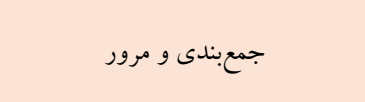 & هشتم \\
\hline
\end{tabular}

سنى افراد مورد مطالعه 11 تا .ب سال بود كه بيشترين درصد يعنى 99/9 كافْته درصد افراد را كروه سنى بr تا وY سال كه اY نفر مجرد و 9 نفر متأهل در اين يثزوهش تعداد ه\& نفر معتاد متجاهر ( •سنفر در كروههاى آزمايش بوده اند. در جدول ب ميانگين و انحر اف استاندارد متغيرهاى يزوهش در

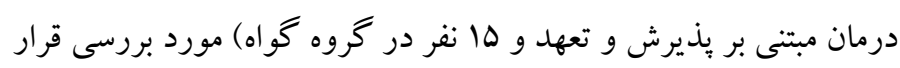
بيش آزمون، يس آزمون و بيخيرى و به تفكيك كروه آزمايش و كنترل

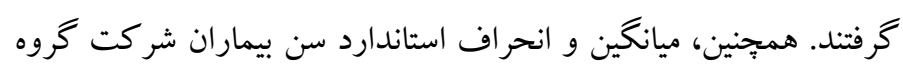

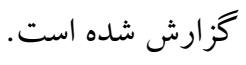


جدول ". ميانتين و انحراف استاندارد نمرات آزمودنى ها در متغير هاى ثخوهش

\begin{tabular}{|c|c|c|c|c|c|c|c|}
\hline \multicolumn{6}{|c|}{ كروه } & \multirow{3}{*}{ آزمون } & \multirow{3}{*}{ متغير } \\
\hline \multicolumn{2}{|c|}{ كنترل } & \multicolumn{2}{|c|}{ طرحو اره درمانى } & \multicolumn{2}{|c|}{ تعهلد و يذيرش } & & \\
\hline انحراف استاندارد & ميانگين & انحراف استاندارد & ميانگين & انحراف استاندارد & ميانگين & & \\
\hline$\varphi / l r$ & $\Delta r / T r$ & $F / T r$ & $\Delta 1 / A$. & $\Delta / \cdot F$ & $\Delta r / Y$. & ييش آزمون & \\
\hline$r / r q$ & $\Delta \Delta / f$ & $f / .1$ & $\Delta N / q r$ & $r / 9$. & $\Delta N / 9$. & يس آزمون & حq \\
\hline$r / \pi r$ & re/r. & $r / F V$ & $r 9 / .4$ & $r / \Delta$. & $r \mid / \wedge 9$ & ييش آزمون & \\
\hline$r / l v$ & rg/NT & $r / F I$ & $r \Delta / \Delta r$ & $r / 90$ & $\mathrm{rT} / .9$ & بِ آزمون & \\
\hline
\end{tabular}

جدول ع. نمر ات افراد در كروه درمان مبتنى بر يذيرش و تعهد در دوره يِيَيرى r ماهله در متغيرهاى يخوهش

\begin{tabular}{|c|c|c|c|c|}
\hline ماه دوم & ماه اول & شاخص آمارى & 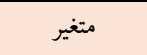 & كروه \\
\hline$\Delta \Delta / r$. & $\Delta 9 / V T$ & ميانگين & \multirow{2}{*}{ خود كار آمدى } & \multirow{4}{*}{ مبتى بر بذيرش و تعهد } \\
\hline$r / 9$. & $r / I r$ & انحراف استاندارد & & \\
\hline rq & rQ/Tr & ميانگين & \multirow{2}{*}{ اشتياق به تغيير } & \\
\hline$r / \mathcal{A V}$ & $r / 19$ & انحر اف استاندارد & & \\
\hline$\Delta \Delta / N$ & $\Delta G / N$ & ميانكين & \multirow{2}{*}{ خود كار آمدى } & \multirow{4}{*}{ طرحو اره درمانى } \\
\hline$F / \cdot 9$ & $F / l 1$ & انحراف استاندارد & & \\
\hline ri/ar & 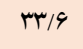 & ميانگين & \multirow{2}{*}{ اشتياق به تغيير } & \\
\hline$r / r r$ & $r / 4 l$ & انحر اف استاندارد & & \\
\hline
\end{tabular}

براى تحليل واريانس اندازههاى مكرر استفاده مىشود. در اين بثزوهش

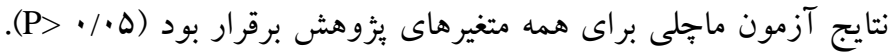

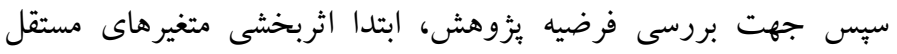

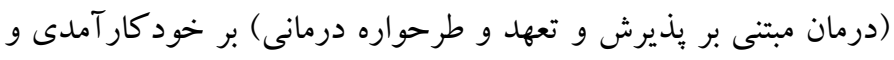

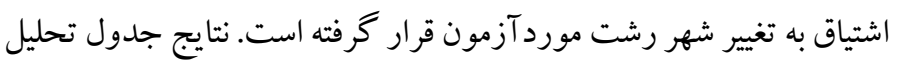

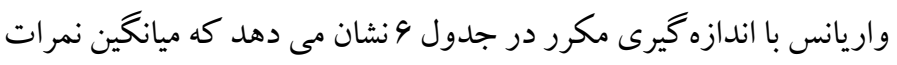

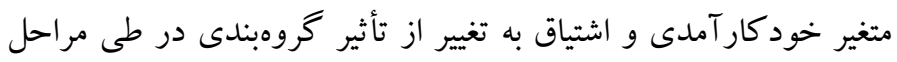

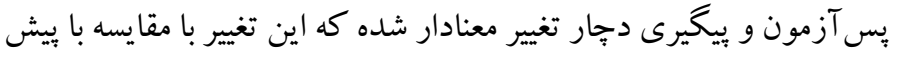

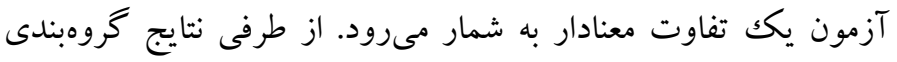
جدول فوق بيانكر آن است كه (درمان مبتنى بر بذيرش و تعهد و طرحواره

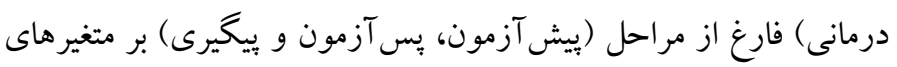

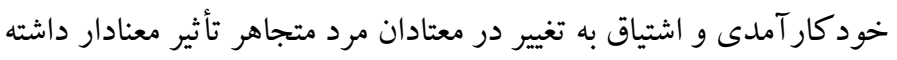
است. نتايج جدول تحليل واريانس با اندازه گيرى مكرر در جدول V نشان مدان مىدهد كه در نمرات آزمودنىها در دوره دو ماهه در متغيرهاى

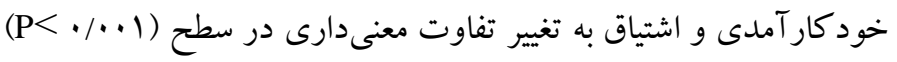

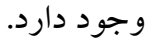

به منظور بررسى فرضيه ى (بين اثربخشى درمان مبتنى بر يذيرش و تعهد و طرحواره درمانى بر افزايش خود كار آمدى و اشتياق به تغيير در افراد معتاد متجاهر تفاوت وجود داردا) از تحليل واريانس مختلط استفاده شد. قبل از به كارگيرى تحليل واريانس مختلط كليه مفروضات اعم آن مورد بررسى

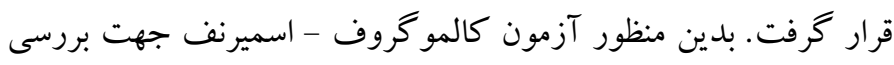

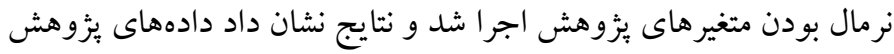

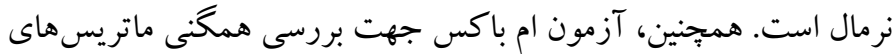

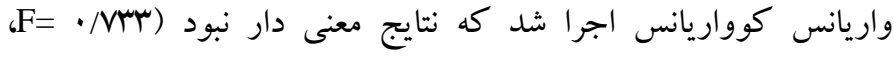

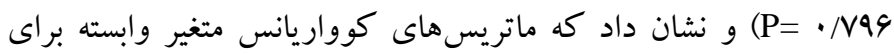

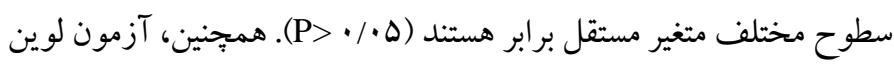

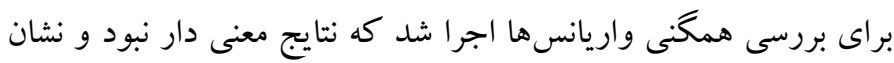

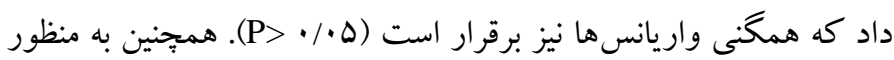

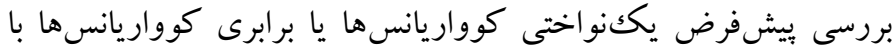

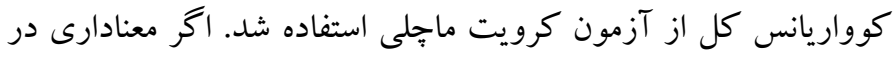

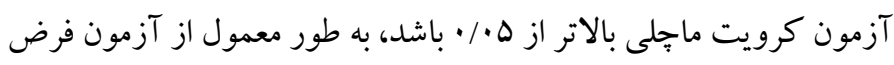

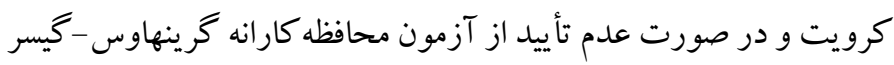


جدوله. آزمون اثرات درون آزمودنى ها در متغيرهاى مورد مطالعه

\begin{tabular}{|c|c|c|c|c|c|c|c|}
\hline مجذور اتا & سطح معنادارى & $\mathrm{F}$ & ميانگين مجذورات & درجه آزادى & مجموع مجذورات & & متغير وابسته \\
\hline$\cdot / \mathrm{VAI}$ &.$/ . \cdot 1$ & $49 / 99$ & Kr/FA & $r$ & $\wedge 9 / 9 \vee \wedge$ & يذيرش كرويت & خود كار آمدى \\
\hline$\cdot /$ AST & $\cdot / \cdot \cdot 1$ & NI/TYK & ITN/FG & r & rVG/ar & يذيرش كرويت & اشتياق به تغيير \\
\hline
\end{tabular}

جدول ا. نتايج تحليل واريانس مكرر در متغير هاى مورد مطالعه در كروه دومان مبتنى بر يذيرش و تعهد

\begin{tabular}{|c|c|c|c|c|c|c|}
\hline مجذور اتا & سطح معنادارى & $\mathrm{F}$ & ميانگين مجذورات & درجه آزادى & مجموع مجذورات & متغير وابسته \\
\hline - /AFG &.$/ \cdot 1$ & VG/AT & $\Lambda 9 / \mathrm{V}$. & 1 & $\Lambda 9 / V$. & خود كار آمدى \\
\hline.$/ 9.1$ & $\%$ & IrG/AF & rVG/.r & 1 & $r V q / \cdot r$ & اشتياق به تغيير \\
\hline
\end{tabular}

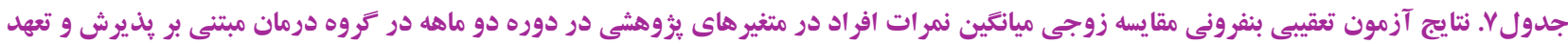

\begin{tabular}{|c|c|c|c|c|c|}
\hline سطح معنادارى & انحراف استاندارد & تفاوت ميانگين & دوره & متغير & كروه \\
\hline$\% \cdot \cdot 1$ & $\cdot / Y 9 \mid$ & 1/Drr & ماه اول- ماه دوم & خو دكار آمدى & \multirow{2}{*}{ بتنى بر يذيرش و تعهد } \\
\hline$\% / .1$ & . & rr/r & ماه اول- ماه دوم & اشتياق به تغيير & \\
\hline$\cdot / \cdot r q$ & $\cdot / r \Delta r$ & 1 & ماه اول- ماه دوم & خود كار آمدى & \multirow{2}{*}{ طرحواره درمانى } \\
\hline$\% \cdot \wedge$ & - /FOF & $1 / 99 \mathrm{~V}$ & ماه اول- ماه دوم & اشتياق به تغيير & \\
\hline
\end{tabular}

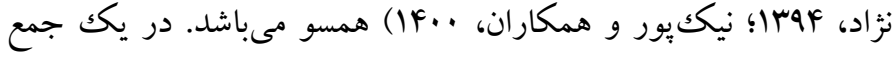
بندى مى توان جنين كفت كه كسانى كه اطمينان كمترى به تو انايى خود

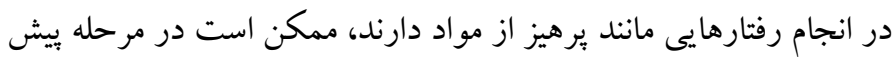

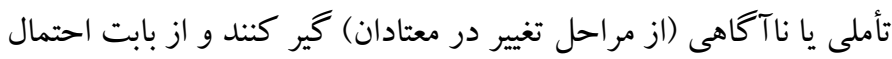
تغيير احساس ناميدى كنند (شباهنگ، باقرى شيخانگفشه و موسوى،

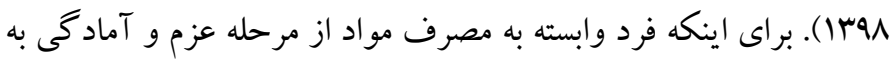

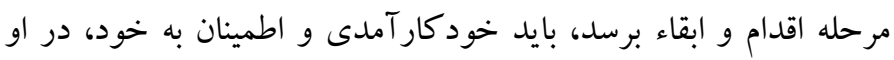

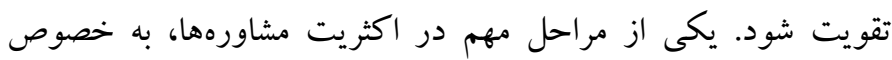

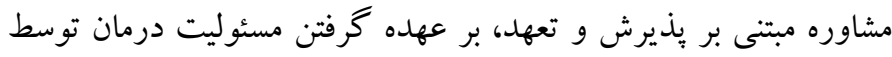

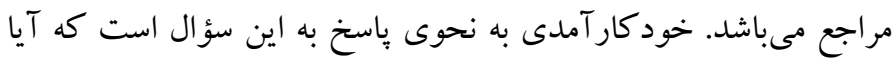

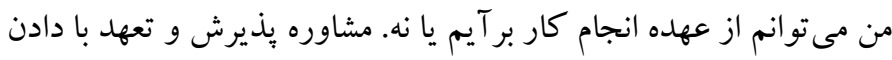

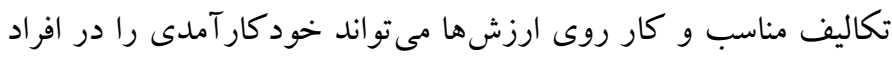

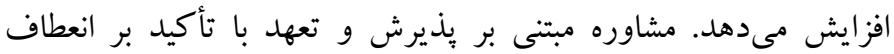

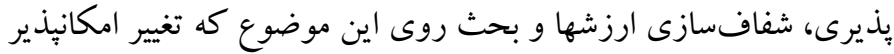
است و همجنين انجام موفقيت آميز تمرينات مختلف، مى تواند به افزايش

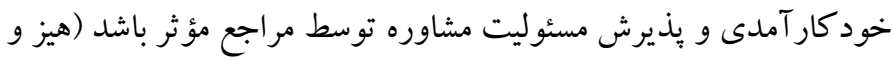

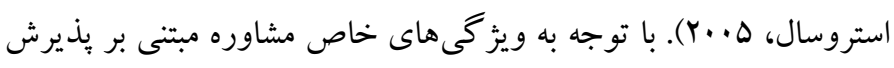
و تعهل و همجنين فنون استفاده شده در اين درمان، به نظر قابل توجيه است
همان گونه كه نتايج جدول V نشان مىدهد تفاوت ميانگين نمرات

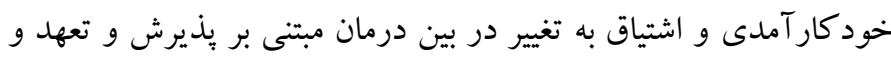

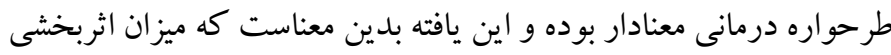
درمان مبتنى بر بذيرش و تعهل و طرحواره درمانى در معتادان متجاهر معنادار بوده و درمانها باعث افزايش خودكار آمدى و اشتياق به تغيير در

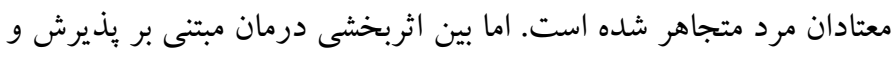

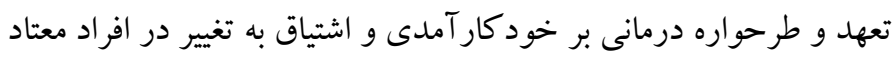
متجاهر تفاوت وجود ندارد.

\section{بحث و نتيجه تيرى}

يُزوهش حاضر با هدف بررسى مقايسه اثربخشى درمان مبتى بر يذيرش و تعهد و طرحواره درمانى بر خود كار آمدى و اشتياق به تغيير در افراد معتاد متجاهر بود. نتايج بُزوهش حاضر نشان داد كه درمان مبتى بر يذيرش و و

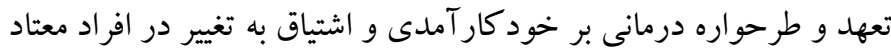
متجاهر مؤثر بوده است. اما بين اثربخشى درمان مبتنى بر يذيرش و تعهد و طرحواره درمانى بر خود كار آمدى و اشتياق به تغيير در افراد معتاد متجاهر تفاوت وجود ندارد. در زمينه اثر بخشى درمان مبتنى بر يذيرش و تعهل بر افزايش خود كار آمدى افراد معتاد متجاهر اين يافته با نتايج يزووهشهاى ييشين (حجازى، حسينى 
از اوايل كودكى تا كنون را رديابى مى كند. با استفاد از اين مدل فرد معتاد

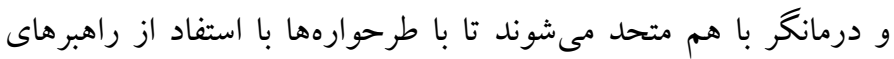

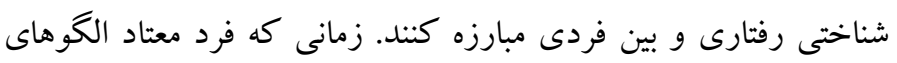

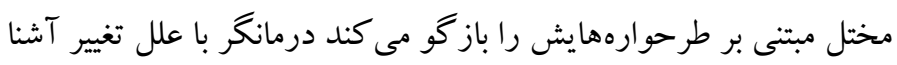

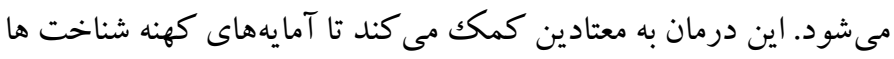
و طرحوارههاى مقاوم خود را شناسايى نمود و با به جالش كشيدن آنها

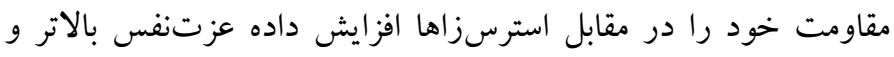

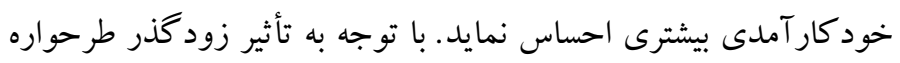

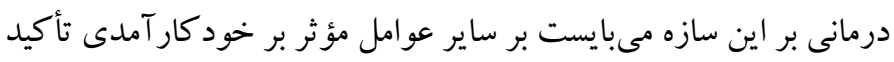

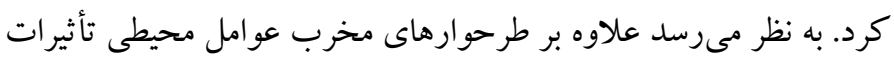

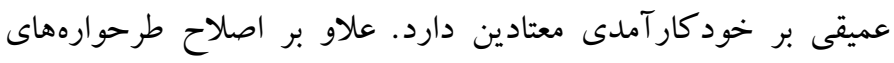

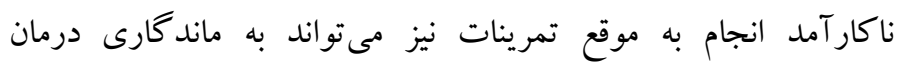
برخود كار آمدى افراد كمك نمايد.

در زمينهى اثربخشى طرحواره درمانى بر اشتياق به تغيير افراد معتاد متجاهر

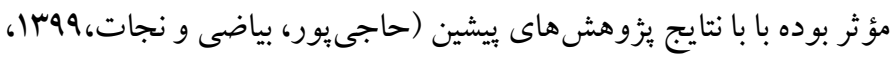

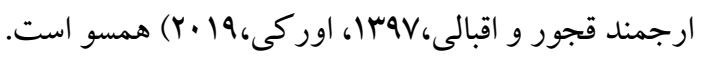
در تبيين اين يافتها مى توان اذعان داشت كه تكنيككهاى شناختى طرحواره درمانى در جلسات درمانى فرصتى براى تغيير شناختوارهها، مهارت آموزى و رويارويى تدريجى براى تصميم گيرى و عملكرد مستقلانه

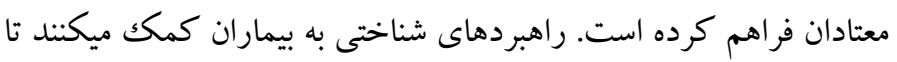

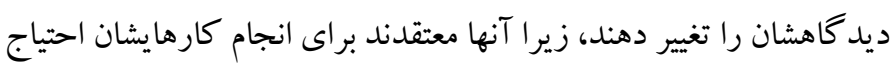
به كمكك مداوم از سوى ديخر ان دارند. راهبردهاى شناختى باعث مى شوند

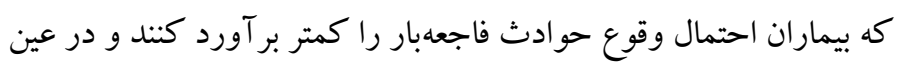

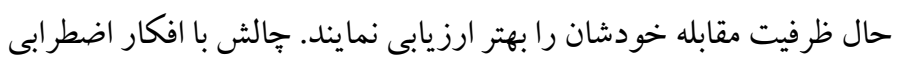
و فاجعهبار كمك مى كند تا اين افراد بيامدهاى اعتياد را بهتر كنترل كنند. علاوه بر اين، راهبردهاى شناختى با برجستهسازى مزاياى تغيير، انخيزه را

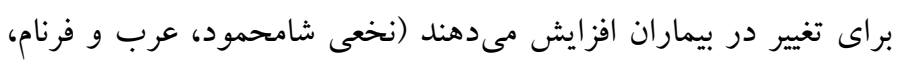

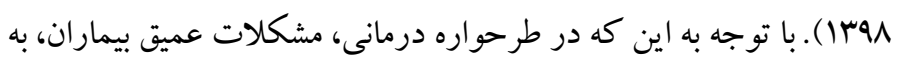

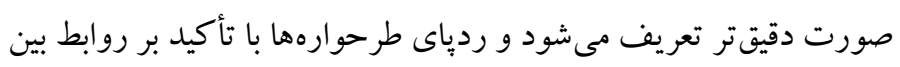

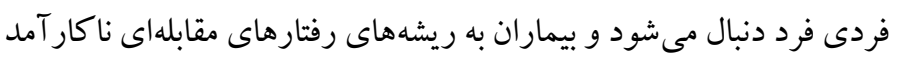

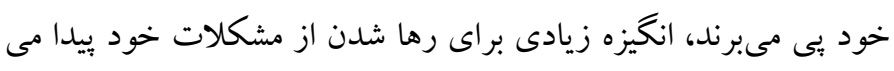

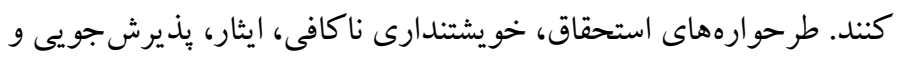

كه مشاوره مبتى بر يذيرش و تعهل باعث افزايش خود كار آمدى در افراد معتاد متجاهر شود. در زمينهى اثربخشى درمان ACT بر اشتياق به تغيير افراد معتاد متجاهر، با

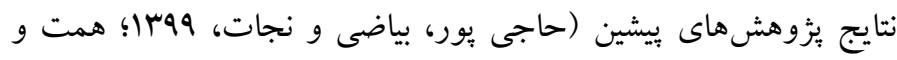

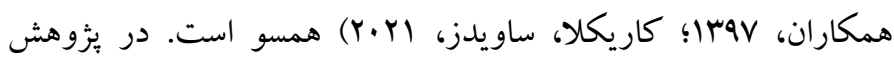

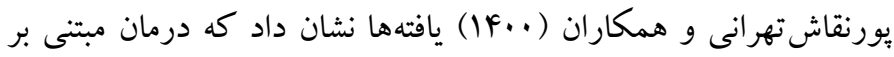
يذيرش و تعهل باعث افزايش يذيرش طرح درمان در مصرف كنند كان

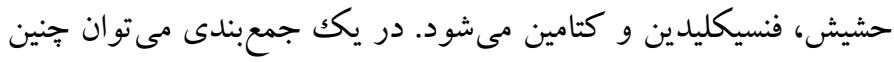

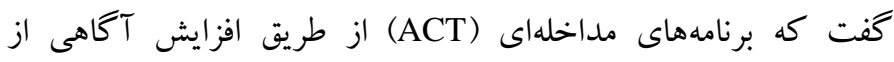

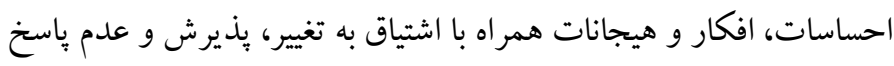

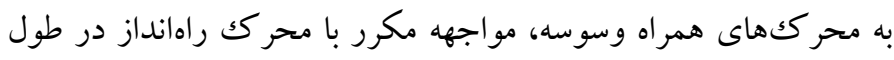
جلساتى كه شر كت كنند كان بذيرش و كسلش شناختى را تمرين مى كنند، توجيه شود. در آسيبشناسى اعتياد بر اساس روان درمانى مبتنى بر يذيرش

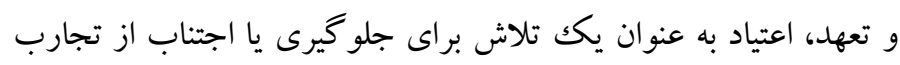
شناختى، عاطفى و جسمانى محسوب مى شود. در تلاش براى اجتناب از

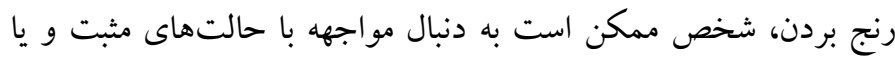
اجتناب از حالتهاى منفى باشد. در تمرينهاى مربوط به گسلش شناختى،

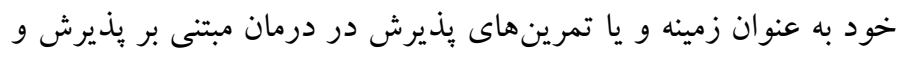

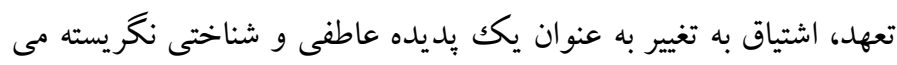

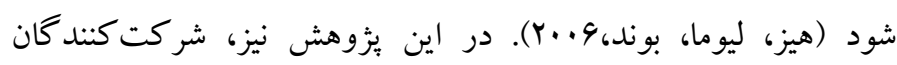

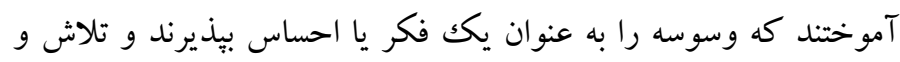
تقلايى براى اجتناب از آن يا سر كوب آن انجام ندهند. شركت كت كند وكان

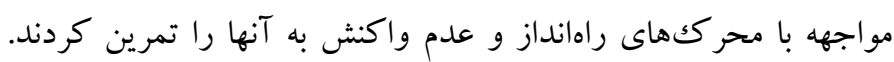
درمان مبتى بر يذيرش و تعهد با هدف مواجهه با وسوسه و هر هيجان

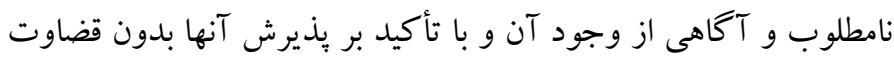
و داورى، مى تواند موجب كاهش وسوسه و اشتياق به تغيير در خود شود.

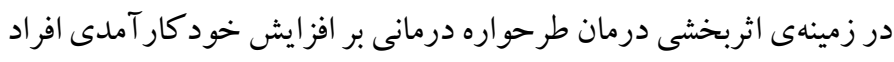

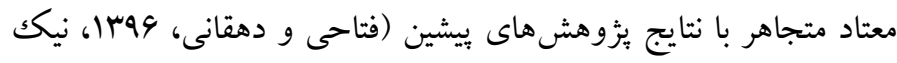

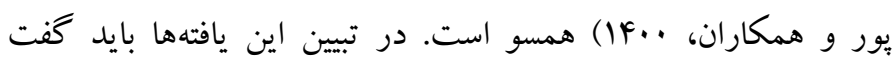

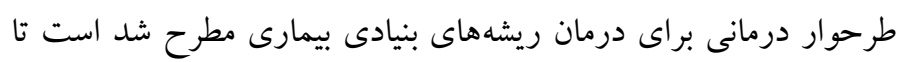

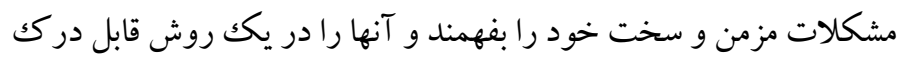
سازماندهى كنند. طرحوار درمانى با تأكيد خاص بر روابط بين فردى بيمار 
(درمان مبتنى بر يذيرش و تعهد و طرحواره درمانى) به شيوه خاص خود

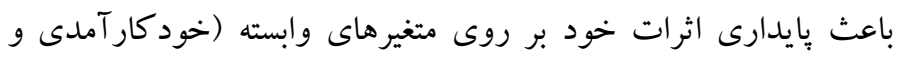

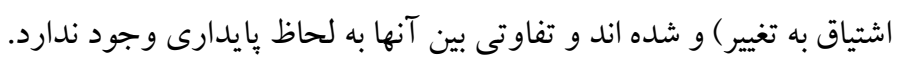

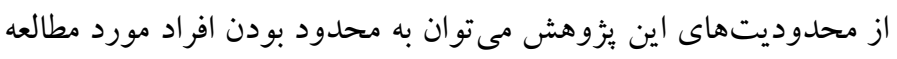

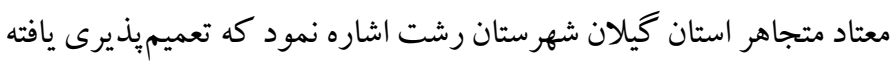

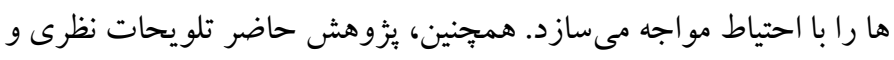

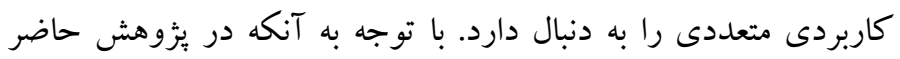

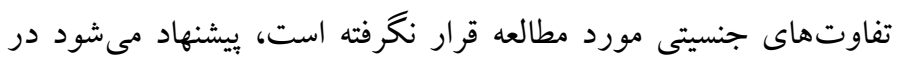

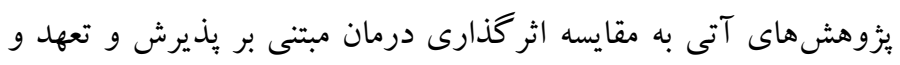

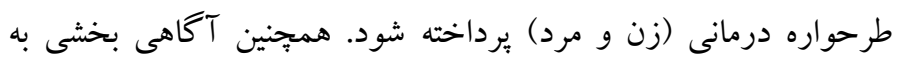

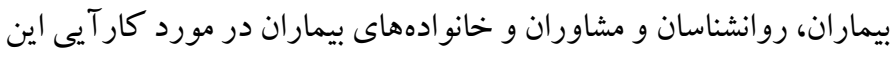
مداخلات و تدوين برنامهايى جهت آشنايى بيشتر بيماران، روانشناسان و

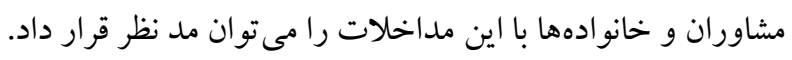

ملاحضات اخلاقى

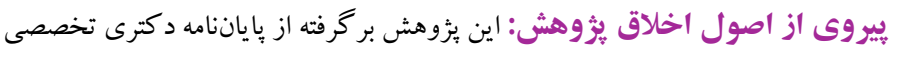

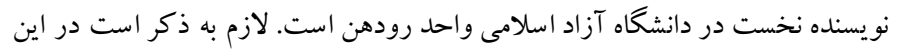

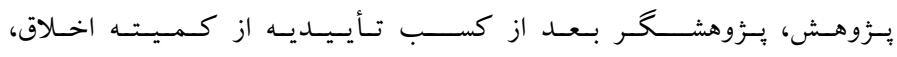

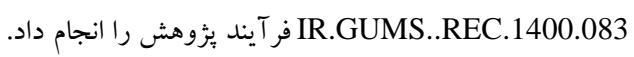

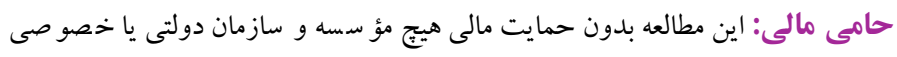

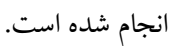

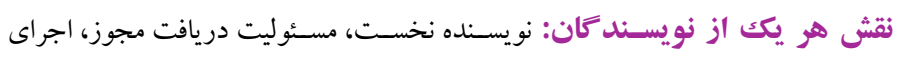

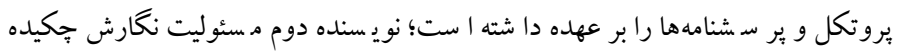

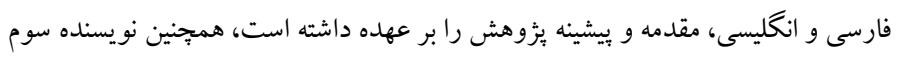

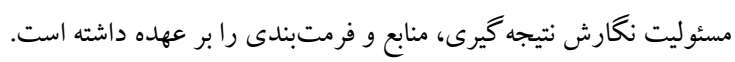

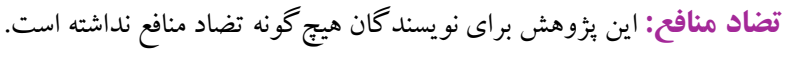

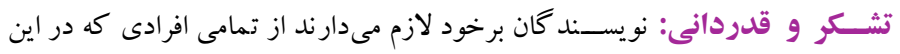
يُزوهش مشار كت و همكارى داشتند، تشكر و قدردانى نمايند.
اطاعت از جمله طرحوارههاى اصلى مصرف مجدد شناسايى شدهاند و در طى جلسات درمانى و همجنين تمايل فرد براى رها شدن از مشكلاتش،

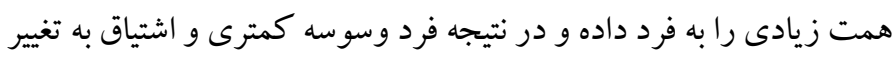

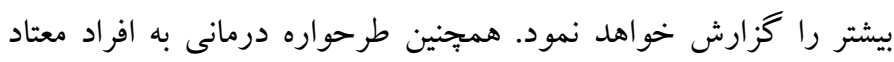

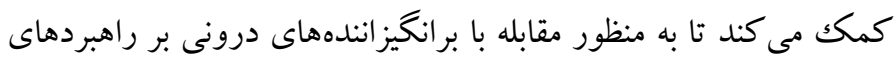

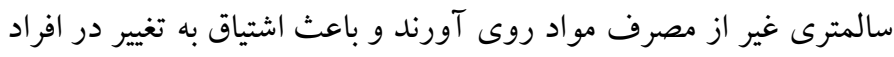
مىشود. همبحنين، نتايج اين يزوهش نشان داد كه تفاوت معنادارى در اثربخشى

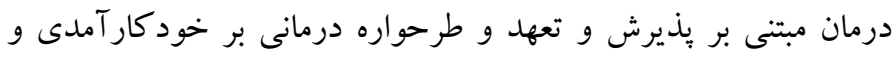

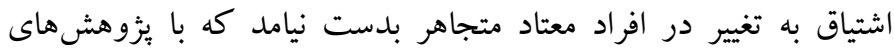

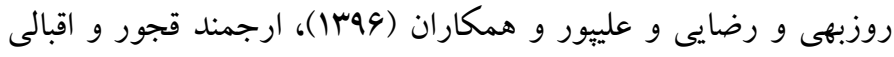

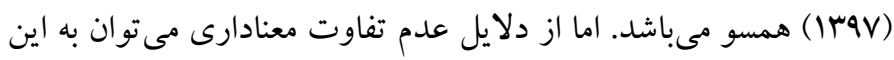

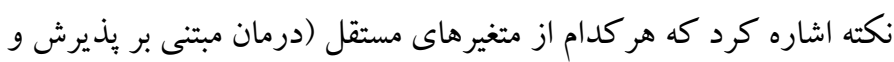

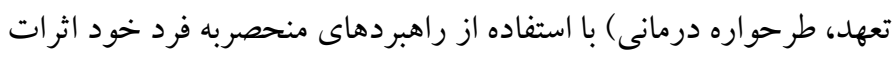
يايدارى بر روى متغيرهاى خودكارآمدى و اشتياق به تغيير در افراد معتاد

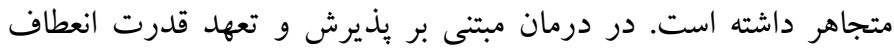

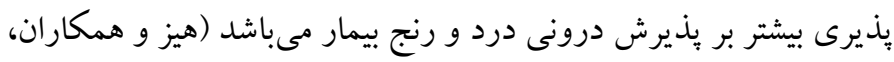

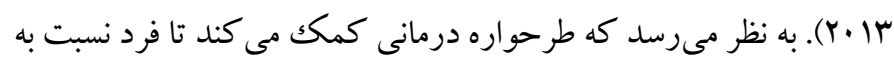

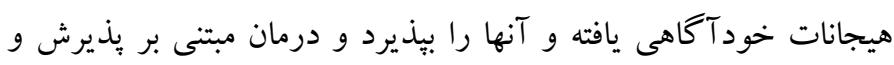

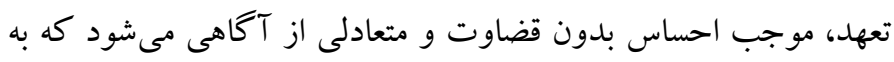

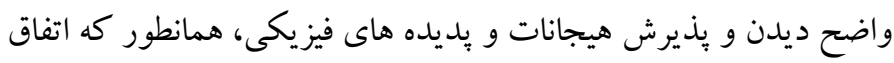

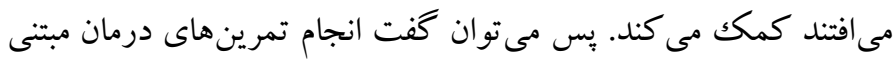

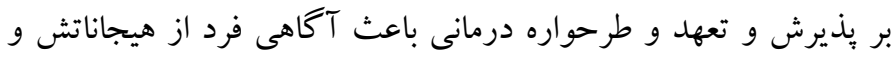

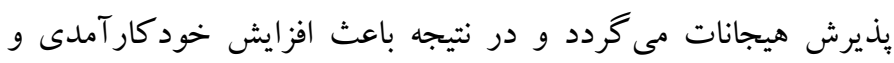

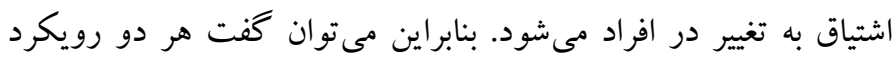




\section{References}

Abiola, T., Udofia, O., Sheikh, T. L., \& Sanni, K. (2015). Assessing Change Readiness and Treatment Eagerness among Psychoactive Substance Users in Northern Nigeria. Journal of Substance Abuse Treatment, 58, 72-77. [Link]

Ardjmand Ghujur, K., \& Eghbali, A. (2018). A Comparing of two Schema Therapy and Acceptance and Commitment Therapy (ACT) Attitudes Effectiveness on Early Maladaptive Schema in Metamphetamine Addicts. Rooyesh, 7(1), 151-178. (Persian). [Link]

Alaghband, SH., Vaziri., SH. (2019). Share of Pleasure seeking, positive affect, negative affect, and sense of self-efficacy in relapse to drug. Rooyesh, 8(2), 183-192. (Persian). [Link]

Ball, S. A., Maccarelli, L. M., LaPaglia, D. M., \& Ostrowski, M. J. (2011). Randomized trial of dualfocused versus single-focused individual therapy for personality disorders and substance dependence. The Journal of nervous and mental disease, 199(5), 319. [Link]

Curry, S. J., Grothaus, L., McBride, C. (1997). Reasons for quitting: Intrinsic and extrinsic motivation for smoking cessation in a population-based sample of smokers. Addictive Behaviors, 22, 727-739. [Link]

Harrop, E., \& Catalano, R. F. (2016). Evidence-Based Prevention for Adolescent Substance Use. Child Adolesc Psychiatr Clin N Am, 25 (3), 387-410. [Link]

Herts, K. L., \& Evans, S. (2021). Schema Therapy for Chronic Depression Associated with Childhood Trauma: A Case Study. Clinical Case Studies, 1534650120954275. [Link]

Hayes, S.C., Levin, M.E., Plumb-Vilardaga, J., Villatte, JL., \& Pistorello, J. (2013). Acceptance and commitment therapy and contextual behavioral science: examining the progress of a distinctive model of behavioral and cognitive therapy. Behav Ther, 44(2), 180-198. [Link]

Hemmat, A, Hemmat, J, Pirzeh, R, Dadashi, M. (2018). The Effectiveness of Group Therapy Based on Acceptance and Commitment to Reduce ObsessiveCompulsive Use of Substance, Anxiety and Depression of Addicts under Methadone Treatment. $J$ Adv Med Biomed Res, 26(117), 109-125. (Persian). [Link]

Hayes, S., Luoma, J. B., \& Bond, f. (2006). Acceptance and commitment therapy: Model, processes and outcomes. Behavior Research and therapy, 44, 1-25. [Link]

Hajipoor, H., Bayazi, M., Nejat, H. (2020). Comparison of the Effectiveness of Schema Group Therapy and Acceptance and Commitment Group Therapy on Substance Abusers' Temptation and Impulsivity. Research in Clinical Psychology and Counseling, 10(1), 39-55. (Persian). [Link]

Oraki, M. (2019). The effectiveness of the schema therapy on depression and relapse in Heroin-dependent individuals. Biquarterly Iranian Journal of Health Psychology, 2(1), 9-18. [Link]

Karekla, M., \& Savvides, S. N. (2021). Smoking cessation avatar-led Acceptance and Commitment Therapy digital intervention: feasibility and acceptability in young adults. Translational behavioral medicine, 11(1), 198-205. [Link]

Karatay, G. \& Bas, N. G. (2017). Effects of Role-Playing Scenarios on the Selfefficacy of Students in Resisting against Substance Addiction: A Pilot Study. The Journal of Health Care Organization, Provision, and Financing, 54, 1-6. [Link]

Miller, W. R., Wilbourne, P. L., \& Hettema, J. (2003). What works? A summary of alcohol treatment outcome research. In R. K. Hester, \&W. R. Miller (Eds.), Handbook of alcoholism treatment approaches: Effective alternatives (3rd ed., pp. 1363). Boston. [Link]

Miller, W. R.; Tonigan, J.S. (1996). Assessing drinkers' motivation for change: the stages of change readiness and treatment eagerness scale (SOCRATES), Psychology of Addictive Behavior, 10(2), 81-89. [Link]

Nikmanesh, Z., Baluchi, M. H., Pirasteh Motlagh, A. A. (2017). The Role of Self -Efficacy Beliefs and Social Support on Prediction of Addiction Relapse. International Journal of High-Risk Behavior and Addiction, 6(1), e21209. [Link]

Nakhee Shamahmood, A A, Arab, A, Farnam, A. (2019). The effectiveness of group schema therapy on early maladaptive schema of traditional and industrial addicts under methadone treatment. $J$ of Psychological Science, 18(82), 1191-201. (Persian). [Link]

Nikpour, F., Khalatbari, J., Rezaei, O., Jomehri., F. (2021). Comparison of the effectiveness of schema therapy approach and acceptance and commitment-based therapy psychological well-being of divorced women. J of Psychological Science, 20(101), 741751. (Persian). [Link] 
Peiper, N. C., Ridenour, T.A., Hochwalt, B., CoyneBeasley, T. (2016). Overview on Prevalence and Recent Trends in Adolescent Substance Use and Abuse. Child Adolesc Psychiatr Clin N Am, 25(3), 349-65. [Link]

Peterson, B.D., Eifert, G.H., Feingold, T., Davidson, S. (2012). Using acceptance and commitment therapy to treat distressed couples: a case study with two couples. Cognitive and Behavior Practice, 16, 430442.dual-earner couples in the sandwiched generation. Social Psychology,74(4), 361-386. [Link]

Pournaghash Tehrani, S., Malekahmad, M., Lavasani, M G. (2021). Assessment of cognitive emotional dementions of personality and compaparison of psychological of prfile of individual with methamphetamine induce psychosis with normal subjects. J of Psychological Science, 20(100), 533536. (Persian). [Link]

Roozbehi, M., Rezaie, M., Alipoor-Dolatabad, A. (2017). Comparing the Effectiveness of Group-Based Acceptance and Commitment and Schematic Therapies on Early Maladaptive Schemas in Addicted Patients of Shiraz Hospitals, Iran. RBS, 15(3), 339-346. (Persian). [Link]

Shabahang., R, Bagheri Sheykhangafshe., F, Mousavi, M. (2019). Effectiveness of Motivational Enhancement Therapy on Addiction Potential and Stages of Change Readiness and Treatment Eagerness. Etiadpajohi, 1 (52), 311-330. (Persian). [Link]

Semlali Wafae, I., Tarik, G., Ahmed, A., Fatima-Zahrae, A., Khadija, K., \& Khaoula, M. (2018). Measurement of early maladaptive schemas in heroin addicts treated with methadone in north of Morocco. European Journal of Investigation in Health, Psychology and Education, 8(3), 185-196. [Link]

Shorey, R. C., Anderson, S. E., \& Stuart, G. L. (2012). Gender differences in early maladaptive schemas in a treatment-seeking sample of alcohol-dependent adults. Substance use \& misuse, 47(1), 108-116. [Link]

Tapia, G., Perez-Dandieu, B., Lenoir, H., Othily, E., Gray, M., \& Delile, J. M. (2018). Treating addiction with schema therapy and EMDR in women with cooccurring SUD and PTSD: A pilot study. Journal of Substance Use, 23(2), 199-205. [Link]

Tremain, D., Freund, M., Wye, P., Wolfenden, L., Bowman, J., \& Dunlop, A. (2016). Provision of chronic disease preventive care in community substance use services: client and clinician report. JSAT, 68(2), 24-30. [Link]

Young, J. E., Klosko, J. S., \& Weishaar, M. E. (2003). Schema Therapy: A Practioner's Guide. New York, NY: Guilford Press. 17. [Link]

Young, J. E. (2003). Schema therapy. New York: Guilford,123-218. [Link]

Young, J. E., Klosko, J. S., \& Weishaar, M. E. (2003). Schema therapy: A practitioner's guide. New York: The Guilford Press. [Link] 